\title{
Forebrain glutamatergic neurons mediate leptin action on depression-like behaviors and synaptic depression
}

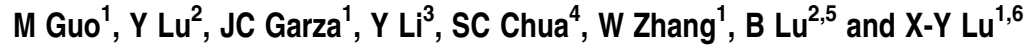

The glutamatergic system has been implicated in the pathophysiology of depression and the mechanism of action of antidepressants. Leptin, an adipocyte-derived hormone, has antidepressant-like properties. However, the functional role of leptin receptor (Lepr) signaling in glutamatergic neurons remains to be elucidated. In this study, we generated conditional knockout mice in which the long form of Lepr was ablated selectively in glutamatergic neurons located in the forebrain structures, including the hippocampus and prefrontal cortex (Lepr CKO). Lepr cKO mice exhibit normal growth and body weight. Behavioral characterization of Lepr cKO mice reveals depression-like behavioral deficits, including anhedonia, behavioral despair, enhanced learned helplessness and social withdrawal, with no evident signs of anxiety. In addition, loss of Lepr in forebrain glutamatergic neurons facilitates $\mathrm{N}$-methyl-D-aspartate (NMDA)-induced hippocampal long-term synaptic depression (LTD), whereas conventional LTD or long-term potentiation (LTP) was not affected. The facilitated LTD induction requires activation of the NMDA receptor GluN2B (NR2B) subunit as it was completely blocked by a selective GluN2B antagonist. Moreover, Lepr CKO mice are highly sensitive to the antidepressant-like behavioral effects of the GluN2B antagonist but resistant to leptin. These results support important roles for Lepr signaling in glutamatergic neurons in regulating depression-related behaviors and modulating excitatory synaptic strength, suggesting a possible association between synaptic depression and behavioral manifestation of behavioral depression.

Translational Psychiatry (2012) 2, e83; doi:10.1038/tp.2012.9; published online 21 February 2012

\section{Introduction}

Depression is a chronic and debilitating mental illness with a $17 \%$ lifetime prevalence and is a major cause of morbidity, disability and mortality. ${ }^{1-3}$ Research in this field has been dominated by the monoamine theory for over 50 years. Currently available pharmacologic treatments for depression primarily target monoamine systems. However, the monoamine-based antidepressants have significant limitations in efficacy, safety and onset of action. Recently, there is increasing preclinical and clinical evidence supporting a role for the glutamatergic system in depression and antidepressant activity. ${ }^{4-8}$ Among glutamate receptor subtypes, the $\mathrm{N}$-methyl-D-aspartate (NMDA) receptor has received the most attention as drugs that modulate NMDA receptor functional activity have demonstrated antidepressant-like properties in animal models ${ }^{9-16}$ and in patients suffering from major depressive disorder. ${ }^{17-20}$

Leptin, a hormone secreted from adipocytes, circulates in the blood and enters the brain where it exerts physiological actions beyond the control of food intake and metabolism. Indeed, systemic or intracranial administration of leptin produces antidepressant-like effects in both rats and mice. ${ }^{21-23}$ Circulating leptin levels are reduced in animals subjected to chronic social defeat or chronic unpredictable stress, two animal models of depression. ${ }^{22,24}$ Although results from clinical investigations have been inconsistent, several studies have found an association between low levels of leptin and major depressive disorders. ${ }^{25-27}$ Of note, a recent study by Lawson et al. ${ }^{28}$ reported an inverse correlation between leptin levels and the severity of depression symptoms. These correlational studies suggest that leptin signaling may be involved in the pathophysiology of major depressive disorders. Leptin exerts its effects by activating the long form of the leptin receptor (Lepr), which is widely but selectively distributed in various brain regions such as the prefrontal cortex and hippocampus, ${ }^{29-31}$ two limbic brain areas implicated in depression. ${ }^{32-34}$ However, whether defects in leptin receptor function in limbic neural circuits contributes to the pathogenesis of depression and whether specific neuronal populations mediate leptin's antidepressant-like activity are not yet known.

In this study, we produced mice in which the long form of the leptin receptor was ablated specifically in glutamatergic neurons in the dorsal forebrain, including the hippocampus and cerebral cortex, using Cre-mediated recombination driven by the promoter of Emx1, a homeobox gene, principally

\footnotetext{
${ }^{1}$ Department of Pharmacology, University of Texas Health Science Center at San Antonio, San Antonio, TX, USA; ${ }^{2}$ Genes Cognition and Psychosis Program, NIMH, National Institutes of Health, Bethesda, MD, USA; ${ }^{3}$ Department of Neurology, School of Medicine, University of Alabama at Birmingham, Birmingham, AL, USA; ${ }^{4}$ Departments of Medicine and Neuroscience, Albert Einstein College of Medicine, New York, NY, USA; ${ }^{5}$ GlaxoSmithKline, R\&D China, Shanghai, China and ${ }^{6}$ Department of Psychiatry, University of Texas Health Science Center at San Antonio, San Antonio, TX, USA

Correspondence: Dr X-Y Lu, Department of Pharmacology, University of Texas Health Science Center at San Antonio, 7703 Floyd Curl Drive, San Antonio, TX 78229 , USA or Dr B Lu, GlaxoSmithKline, R\&D China, Shanghai 201203, China

E-mail: lux3@uthscsa.edu or bai.b.lu@gsk.com

Keywords: behavioral depression; GluN2B subunit; glutamatergic neurons; leptin receptor; NMDA receptors; synaptic depression

Received 9 January 2012; accepted 9 January 2012
} 
expressed in forebrain glutamatergic neurons. ${ }^{35-37}$ We characterized the behavioral, neuroendocrine and electrophysiological phenotypes of these mice. Moreover, we examined the responses of these mice to the antidepressant-like behavioral effects of a GluN2B antagonist and leptin. Our results suggest that Lepr signaling in forebrain glutamatergic neurons is critical for regulating depression-like behaviors and induction of hippocampal long-term synaptic depression.

\section{Materials and methods}

Animals. Emx1 is expressed principally in glutamatergic neurons in the forebrain including cerebral cortex and hippocampal formation. ${ }^{35-37}$ To generate mice with ablation of the long form of Lepr in forebrain glutamatergic neurons, Lepr flox/flox mice, in which loxP sites flank exon 17 that contains the Box 1 motif crucial for leptin signal transduction, ${ }^{38}$ were mated with Emx1-Cre mice, in which Cre recombinase was driven by the promoter of the Emx1 gene. ${ }^{39}$ The Lepr flox/+, Emx1-Cre offsprings were then bred with Lepr flox/flox mice for 4-5 generations. Genomic DNA was extracted and used as the template for PCR-based genotyping. For verification of the Leprflox/flox alleles, the PCR products were amplified using the primers $5^{\prime}$-ATGCTATCGACAAGCAGCAGAATGA$3^{\prime}$ and 5'-CAGGCTTGAGAACATGAACACAACAAC-3'. The presence of the LOXP sites was verified by digesting the PCR product with HindIII. The Emx1-Cre allele was verified using the primers 5'-CACTCATGGAAAATAGCGATC-3' and 5'ATCTCCGGTATTGAAACTCCAGCGC-3'. All mice were housed in groups of four or five on a $14 \mathrm{~h}$ light $/ 10 \mathrm{~h}$ dark cycle (lights on at $0700 \mathrm{~h}$ ) with ad libitum access to food and water. All procedures were approved by the Institutional Animal Care and Use Committee at the University of Texas Health Science Center at San Antonio and carried out in accordance with the National Institutes of Health Guide.

Cre expression. The Emx1-Cre knock-in construct contains a lacZ gene coding for nuclear-localized $\beta$-galactosidase that is linked to an internal ribosomal entry site followed by a nuclear-localized Cre-coding region. ${ }^{40}$ This allows for coexpression of Cre and $\beta$-galactosidase. To confirm the expression pattern of Cre in the Lepr flox/flox mouse brain, lacZ expression was used as readout for cell-specific Cre expression. Immunoreactivity of $\beta$-galactosidase was performed as described in detail below.

Reverse transcription-PCR. Cortex, hippocampus and hypothalamus of Lepr flox/flox $(f \mathrm{WT})$ and Lepr flox/flox, Emx1Cre/+ (Lepr conditional knockout (Lepr cKO)) mice were dissected and total RNA was extracted using Trizol reagent (Invitrogen, Carlsbad, CA, USA). SuperScript II reverse transcriptase (Invitrogen) was used to generate complementary DNA (cDNA) using the oligo(dT) 25 . The reaction mixture consisted of $4 \mu \mathrm{g}$ of total RNA, $500 \mathrm{ng}$ oligo(dT) $)_{25}$, $4 \mu \mathrm{l}$ of $5 \times$ First-Strand buffer, $10 \mathrm{~mm}$ dithiothreitol, 40 units of RNaseOUT (Invitrogen) and 200 units of SuperScript II reverse transcriptase (Invitrogen). The resulting cDNA was used for PCR amplification of Lepr exon 17 or $\beta$-actin with
Accuprime pfx Supermix (Invitrogen). The PCR mix consisted of $22 \mu \mathrm{l}$ of the Accuprime pfx Supermix with $1 \mu \mathrm{l}$ of each primer $(10 \mu \mathrm{M}$ stock) and $1 \mu \mathrm{l}$ cDNA. The conditions for PCR were $94{ }^{\circ} \mathrm{C}$ for $5 \mathrm{~min}$, followed by 35 cycles of $94{ }^{\circ} \mathrm{C}$ for $1 \mathrm{~min}, 60^{\circ} \mathrm{C}$ for $1 \mathrm{~min}$ and $72^{\circ} \mathrm{C}$ for $1 \mathrm{~min}$, followed by a final incubation at $72^{\circ} \mathrm{C}$ for $10 \mathrm{~min}$. The primer sequences used to amplify each product are as follows: Lepr exon 17, forward: 5'-GGGACGATGTTCCAAACCCCA-3' and reverse: 5'-AGGCTCCAGAAGAAGAGGACC-3'; $\beta$-actin, forward: 5'AGCCATGTACGTAGCCATCC-3' and reverse: 5'-TGTGGT GGTGAAGCTGTAGC-3'. The PCR products were analyzed on a $1 \%$ agarose gel with ethidium bromide.

Real-time reverse transcription-PCR. Primers specific for exon 17 of Lepr or $\beta$-actin were used to amplify a single PCR product from each cDNA sample. Real-time PCR was performed on a Realplex2 Mastercycler (Eppendorf, Westburg, NY, USA) and analyzed using Mastercycler EP Realplex, version 1.5. The amplification mixture contained $25 \mu \mathrm{l}$ of the Power SYBRGreen PCR Master Mix (Applied Biosystems, Carlsbad, CA, USA), $1 \mu$ l of each primer ( $10 \mu \mathrm{M}$ stock), $1 \mu \mathrm{l}$ of cDNA template and $22 \mu \mathrm{l}$ of PCR-grade water. The cycling conditions began with a hot start at $95^{\circ} \mathrm{C}$ for 5 min followed by 40 cycles of 95,60 and $72^{\circ} \mathrm{C}$ for $1 \mathrm{~min}$ each. The reactions were performed in duplicate. Control reactions consisting of master mix and primers but excluding cDNA template were run in parallel. The $\mathrm{Ct}$ values for each duplicate were averaged and used for quantification. The relative amount of mRNA for Lepr exon 17 for each sample was normalized to $\beta$-actin mRNA using the following formula: $2^{\text {(CTexon } 17-\text { CT } \beta \text {-actin) }}$.

Measurement of body weight and body composition. For Lepr cKO mice and $f \mathrm{WT}$ littermate controls, body weight was recorded once per week from 4 to 12 weeks of age. Body composition in 14-week-old mice was measured by dualenergy X-ray absorptiometry (GE Medical Systems, Madison, WI, USA). The instrument was calibrated using the phantom mouse model accompanied with the machine, and quality control was performed before the detection of animals.

Behavioral procedures. All behavioral tests used adult mice (9-12 weeks old) and were performed during the late light phase except sucrose preference that was measured every $24 \mathrm{~h}$. On the test day, animals were singly housed in a new cage with some home cage bedding to avoid the stressful effect of removal from their home cage. Animals were transferred to the testing room and habituated to the room conditions for 3 to $4 \mathrm{~h}$ before the beginning of the experiments. After each individual test session, the apparatus was thoroughly cleaned with $20 \%$ alcohol to eliminate the odor and trace of the previously tested animals. All behaviors were scored by experimenters who were blind to the treatments and genotypes.

Locomotor activity. On the testing day, the home cage lid was replaced by clear Plexiglas to enable recording of animal's activity using a CCD (charge-coupled device) camera mounted above the cage. Locomotor activity was monitored and recorded for $30 \mathrm{~min}$. The total distance traveled in $30 \mathrm{~min}$ 
was measured in 2 min bins by using the Noldus EthoVision 3.0 system (Noldus Information Technology, Leesburg, VA, USA).

Rotarod test. Mice were trained for 2 days on the rotarod at fixed speeds of 5,15 and 30 r.p.m. for 5 min each. On the third day, mice were tested on the rotarod at accelerating speeds from 4 to 40 r.p.m. over $5 \mathrm{~min}$. The latency for each mouse to fall from the rod was recorded.

Behavioral despair tests. Mice were assessed in the tail suspension test and the forced swim test. The tail suspension apparatus was a wooden box $(30 \times 30 \times 30 \mathrm{~cm})$. The front of the box was open, and a horizontal bar was placed $1 \mathrm{~cm}$ from the top with an attached vertical bar hanging down in the center. Mice were individually suspended by the tail to the vertical bar with adhesive tape affixed $2 \mathrm{~cm}$ from the tip of the tail. A CCD camera was positioned in front of the tail suspension test box and the animal's behavior was recorded for $6 \mathrm{~min}$. Immobility is defined as the absence of any limb or body movements, except those caused by respiration. For the forced swim test, mice were placed in a clear Plexiglas cylinder $\left(25 \mathrm{~cm}\right.$ high; $10 \mathrm{~cm}$ in diameter) filled with $24^{\circ} \mathrm{C}$ water to a depth of $15 \mathrm{~cm}$. Fresh water was used for each animal. A CCD camera positioned directly above the cylinder recorded the swim session. In a 6-min test session, the first $2 \mathrm{~min}$ were designated as a habituation period and the duration of immobility during last $4 \mathrm{~min}$ was measured using Noldus EthoVision 3.0 system (Noldus Information Technology). ${ }^{21}$

For evaluating the antidepressant-like behavioral effects of leptin (R\&D Systems, Minneapolis, MN, USA) or Ro25-6981 (Sigma, St Louis, MO, USA), the drugs were dissolved in saline immediately before use and administered intraperitoneally to mice $30 \mathrm{~min}$ before the tail suspension test or the forced swim test. The testing procedures and scoring methods were the same as described above.

Sweet solution preference. Mice were habituated to drinking from two bottles of water for 1 week before testing. To measure the preference for sweet solutions, the animals were singly housed and tested with one bottle of water and one bottle of either $1 \%$ sucrose or $0.01 \%$ saccharin for 4 consecutive days. Water and sucrose or saccharin intake were measured daily and the position of two bottles was switched every day to avoid side preference. Sucrose or saccharin preference was calculated as the mass of sucrose or saccharin solution consumed over the total mass of fluid intake.

Learned helplessness test. This test was performed in a shuttle cage that was divided equally into two chambers with an auto-controlled guillotine door. Learned helplessness was induced in mice by administering 200 scrambled, inescapable foot shock (0.3 mA shock amplitude, 2-s duration, 16-s average interval) over a 1-h session. Control animals were exposed to the apparatus for the same period of time without receiving foot shocks. Escape performance was tested $24 \mathrm{~h}$ later in the same shuttle chamber. Each mouse was given 30 shuttle escape trials with $25 \mathrm{~s}$ maximum duration and 30-s intervals. On the first five trials, a sound cue and the shock took place at the same time as the door to the safe compartment opened. For the remaining trials, the door opened $2 \mathrm{~s}$ after the shock was delivered. Each trial was terminated when the mouse crossed into the non-shock compartment. Latency to escape and the number of escape failure were recorded automatically by the Graphic State software (Coulbourn Instruments, Allentown, PA, USA).

Hot-plate test. Pain sensitivity was assessed by detecting the reflexes in the hot-plate test. The surface of the hot plate was heated to a constant temperature of $55^{\circ} \mathrm{C}$. Mice were placed on the hot plate with surrounded wall. The duration of the test session was a maximum of $30 \mathrm{~s}$. The latency to respond with hindpaw lick, hindpaw flick or jump was recorded. The mouse was immediately removed from the hot plate and returned to its home cage. If the mouse did not respond, the test was terminated after $30 \mathrm{~s}$.

Chronic social defeat. This was conducted using a residentintruder paradigm as previously reported. ${ }^{41-44}$ Briefly, each male AWT and Lepr cKO mouse was individually introduced to the home cage of an unfamiliar aggressive CD1 resident mouse for $10 \mathrm{~min}$ and physically defeated. After the defeat, the resident CD1 mouse and the intruder mouse were housed together but separated by a perforated plastic divider to allow visual, olfactory and auditory contact for the remainder of the 24-h period. Mice were exposed to a new resident CD1 mouse and subjected to social defeat each day for 10 consecutive days. Non-defeated control mice were housed two per cage in cages identical to those used for the socially defeated mice. At $24 \mathrm{~h}$ after the last social defeat session, mice were subjected to the social interaction/avoidance test, which was performed in a $40 \times 40 \mathrm{~cm}$ arena with infrared light illumination. The approach-avoidance behavior of mice was recorded with a video tracking system. Each test consisted of two 2.5-min sessions. In the first 2.5-min 'no target' session, the mouse was introduced to the open arena with an empty wire mesh cage $(10 \times 6.5 \times 5 \mathrm{~cm})$ as indicated in Figure $2 \mathrm{~g}$. For the second 2.5-min session with target, an unfamiliar CD1 male mouse was placed into the wire mesh cage. The wire mesh cage allowed visual and olfactory interactions between the test mouse and the target CD1 mouse and prevented direct physical contact. The time spent in the 'interaction zone' $(25 \times 14 \mathrm{~cm})$ located around where the wire mesh cage was located and in the 'avoidance zone' (on the side opposite to the interaction zone, $40 \times 10 \mathrm{~cm}$ ) were measured using EthoVision 3.0 software. Social preference ratio was calculated as time in the interaction zone/(time in the interaction zone + time in the avoidance zone).

Elevated plus maze (EPM). The EPM was made of black acrylic, with four arms ( $30 \mathrm{~cm}$ long and $5 \mathrm{~cm}$ wide) arranged in the shape of a 'plus' sign and elevated to a height of $70 \mathrm{~cm}$ from the floor. ${ }^{45}$ Two arms have no side or end walls (open arms). The other two arms have side walls and end walls (12 cm high) but are open on top (closed arms). The open and closed arms intersect, at a central $5 \times 5 \mathrm{~cm}$ square platform giving access to all arms. The mice were placed in the central square facing the corner between a closed arm and an open arm, and their exploration was videotaped. The numbers of entries and the time spent on each arm were 
measured. Entry was defined as all four paws being positioned within one arm. The degree of anxiety was assessed by calculating the percentage of open arm entries (entries into the open arms/total entries into all arms) and percentage of open arm time (time spent in the open arms/total time spent in all arms).

Open-field test. The apparatus was made of plastic coated wood and consisted of a $60 \times 60 \mathrm{~cm}$ open arena with $40 \mathrm{~cm}$ high walls. The open field arena was divided into nine equal squares. The center square was defined as the central zone, in which the animal's activity is usually regarded as a measure of anxiety. The entire test arena was adjusted to even illumination. Mice were placed in the center of the arena, and their activity in the arena was recorded for $5 \mathrm{~min}$ using a CCD camera. The percent time mice spent in the central zone and the total distance traveled in the open arena were quantified using the Noldus EthoVision 3.0 system. The overall motor activity during the open field test was assessed as the total distance traveled.

Light/dark choice. This test is based on a natural conflict of a mouse between the innate aversion to brightly illuminated areas and the exploration of a novel environment. The apparatus consisted of two equally sized compartments $(17.8 \times 17.8 \times 30.5 \mathrm{~cm})$ divided by a wall with an opening at the floor level. The light compartment was brightly illuminated with light intensity of 700 lux; and the dark compartment was black walled. Mice were placed individually in the center of the light compartment facing away from the opening. The number of transitions between two compartments and time spent in the light compartment were recorded over $5 \mathrm{~min}$.

Visual cliff test. This test measures the ability to avoid a visual cliff. ${ }^{45}$ The apparatus is used to evaluate the ability of the animal to see the drop-off at the edge of a horizontal surface. A box with the inner surface covered with checkerboard paper was connected to a vertical drop of $0.7 \mathrm{~m}$. A sheet of clear Plexiglas provided a solid horizontal surface in spite of the visual appearance of a cliff. Each mouse was subjected to 10 consecutive trials. Normal mice stop at the 'edge'. The visually impaired animals cannot detect the 'cliff' and will move forward across the 'cliff' without pause.

Mice that were naïve to behavioral testing were used for assessing locomotor activity, tail suspension, forced swim, sweet solution preference, learned helplessness, chronic social defeat and EPM. The rotarod and visual cliff tests were performed on the mice used for the locomotion test; the hotplate test was performed on the mice following the learned helplessness test; the open-field test and light/dark choice were performed using the same cohort of mice.

Plasma corticosterone, insulin and leptin level analysis. Plasma corticosterone was assayed using the radioimmunoassay method. Briefly, 10- $\mu$ l duplicate samples of plasma were heated at $70^{\circ} \mathrm{C}$ for $30 \mathrm{~min}$ to denature corticosterone-binding protein, and incubated overnight with corticosterone antibody (Chemicon International, Temecula, CA, USA) and $\left[{ }^{3} \mathrm{H}\right]$ corticosterone (PerkinElmer, Boston, MA, USA). Free and bound corticosterone were separated by incubation with charcoal for $15 \mathrm{~min}$. The levels of plasma insulin and leptin were measured using mouse insulin and leptin ELISA kits, respectively (Alpco Diagnostics, Salem, $\mathrm{NH}$, USA). Plasma was diluted 1:5 in a dilution buffer and immobilized in 96-well plates coated with specific antibodies conjugated to horseradish peroxidase and quantified by a chromogenic substrate.

Immunohistochemistry. Immunohistochemistry was performed as described previously. ${ }^{46}$ Mouse brains were fixed in $4 \%$ paraformaldehyde and cut into $40-\mu \mathrm{m}$ coronal sections. For the detection of $\beta$-galactosidase in Lepr ${ }^{\text {flox/flox }}$, $E m \times 1-C r e /+$ mice, the brain sections were first incubated with rabbit anti- $\beta$-galactosidase (1:100, Abcam, Cambridge, MA, USA), followed by goat anti-rabbit conjugated to AlexaFluor 488 (1:400, Molecular Probes, Eugene, OR, USA).

In situ hybridization. Antisense cRNA probes directed against the sequence of the mouse leptin receptor Cterminus glucocorticoid receptor and corticotropin-releasing hormone mRNA were labeled with $\mathrm{S}^{35}$-UTP (uridine triphosphate) and $\mathrm{S}^{35}$-CTP (cytidine triphosphate) (PerkinElmer, Waltham, MA, USA) using the standard transcription system as described in our previous studies. ${ }^{47,48}$ Briefly, coronal brain sections were cut and mounted onto polylysine-coated slides. The brain sections were fixed in 4\% paraformaldehyde for $1 \mathrm{~h}$, rinsed in $2 \times \mathrm{SSC}(300 \mathrm{~mm} \mathrm{NaCl}, 30 \mathrm{~mm} \mathrm{Na}$ citrate, $\mathrm{pH} 7.2)$ three times ( $5 \mathrm{~min}$ each). The slides were then acetylated in $0.1 \mathrm{M}$ triethanolamine $(\mathrm{pH} 8.0)$ with $0.25 \%$ acetic anhydride for $10 \mathrm{~min}$ and dehydrated through a graded series of alcohol (50-100\%). Hybridization was conducted by the addition of $70 \mu \mathrm{l}$ of the diluted radiolabeled probe to the slide and incubation at $55^{\circ} \mathrm{C}$ overnight. The slides were rinsed in $2 \times$ SSC and incubated in RNase A buffer $\left(200 \mathrm{mg} \mathrm{ml}^{-1}\right)$ for $1 \mathrm{~h}$ at $37^{\circ} \mathrm{C}$, followed by a series of washes of increasing stringency $(2 \times, 1 \times, 0.5 \times$ SSC $)$. Finally, the slides were placed in $0.1 \times$ SSC at $70^{\circ} \mathrm{C}$ for $1 \mathrm{~h}$, rinsed in distilled water, dehydrated in a graded series of alcohol and were exposed to X-ray film.

Electrophysiology. Coronal hippocampal slices $(400 \mu \mathrm{m})$ were prepared from 8- to 12-week-old male mice. Briefly, hippocampal slices were cut using a vibrating microtome (NVSLM1, WPI, Sarasota, FL, USA) in ice-cold slicing buffer (in mM: $127 \mathrm{NaCl}, 26 \mathrm{NaHCO}_{3}, 1.2 \mathrm{KH}_{2} \mathrm{PO}_{4}, 1.9 \mathrm{KCl}, 1.1$ $\mathrm{CaCl}_{2}, 2 \mathrm{MgSO}_{4}$ and 10 D-Glucose) bubbled with $95 \% \mathrm{O}_{2}$ and $5 \% \mathrm{CO}_{2}$. Slices were then transferred to a holding chamber containing oxygenated artificial cerebrospinal fluid (ACSF; in mM: $127 \mathrm{NaCl}, 26 \mathrm{NaHCO}_{3}, 1.2 \mathrm{KH}_{2} \mathrm{PO}_{4}, 1.9 \mathrm{KCl}$, $2.2 \mathrm{CaCl}_{2}, 1 \mathrm{MgSO}_{4}$ and $10 \mathrm{D}$-Glucose) for $30 \mathrm{~min}$ at $34{ }^{\circ} \mathrm{C}$ and for another $30 \mathrm{~min}$ at $22^{\circ} \mathrm{C}$ for recovery, and then transferred to a submersion recording chamber while continually perfused with $32{ }^{\circ} \mathrm{C}$ oxygenated ACSF (rate: $2 \mathrm{ml} \mathrm{min}^{-1}$ ). Slices were equilibrated for at least $15 \mathrm{~min}$ before each recording.

ACSF-filled glass electrodes (resistance $<1 \mathrm{M} \Omega$ ) were positioned in the stratum radiatum of area CA1 for extracellular recording. Synaptic responses were evoked by stimulating Schaffer collaterals with $0.2 \mathrm{~ms}$ pulses with a bipolar tungsten electrode (WPI) once every $15 \mathrm{~s}$. The stimulation intensity was systematically increased to determine the 
maximal field excitatory postsynaptic potential (fEPSP) slope and then adjusted to yield $40-60 \%$ of the maximal (fEPSP) slope. Experiments with maximal fEPSPs of $<0.5 \mathrm{mV}$ or with substantial changes in the fiber volley were rejected. After recording of a stable baseline for $15 \mathrm{~min}$, long-term potentiation (LTP) was induced by one $1 \mathrm{~s}$ per $100 \mathrm{~Hz}$ stimulus train, and long-term depression (LTD) was induced by 900 pulses delivered with a frequency of $1 \mathrm{~Hz}$ in the absence or presence of L-trans-pyrrolidine-2,4-dicarboxylic acid (PDC; Sigma), a glutamate transporter inhibitor, and ifenprodil (Sigma), a GluN2B selective antagonist.

Field EPSPs were recorded (AxoClamp 2B amplifier, Axon Instruments, Foster City, CA, USA), filtered at $1 \mathrm{kHz}$, digitized at $10 \mathrm{kHz}$ (Axon Digidata 1322A) and stored for off-line analysis (Clampfit 9). Whole-cell recordings from CA1 pyramidal neurons were made using an Axopatch 200B amplifier (Axon Instruments), sampled at $10 \mathrm{kHz}$, digitized by a DigiData 1322A and later analyzed off-line by ClampFit (Axon software). Whole-cell patch pipettes with resistances ranging between 3 and $7 \mathrm{M} \Omega$ were pulled using standard borosilicate capillaries by an upright PB-7 electrode puller (Narishige, East Meadow, NY, USA) and were filled with a Csgluconate-based patch solution (in mM: $125 \mathrm{Cs}$-gluconate, 20 $\mathrm{CsCl}, 10 \mathrm{NaCl}, 2 \mathrm{Mg}-\mathrm{ATP}, 0.3 \mathrm{Na}-\mathrm{GTP}, 2.5 \mathrm{QX314}, 10$ PIPES, 0.2 EGTA, pH 7.3 adjusted with $\mathrm{CsOH}$ ). Synaptic currents were evoked by monopolar stimulation at a rate of $0.05 \mathrm{~Hz}$ via a silver wire housed in an ACSF-filled glass electrode (1-2M $\Omega$ ) placed in the Schaeffer collaterals. Magnitude and rate of extracellular stimulation were controlled with a Master-8 stimulator (AMPI, Jerusalem, Israel).

To determine the $\alpha$-amino-3-hydroxy-5-methyl-4-isoxazolepropionic acid receptor (AMPAR)/NMDA receptor (NMDAR) current ratio, whole-cell recordings were performed at a holding potential of $+40 \mathrm{mV}$ in the presence of a $\gamma$-Aminobutyric acid A receptor antagonist, picrotoxin $(50 \mu \mathrm{M}$, Sigma). Baseline responses were recorded in the absence of APV (2-amino-5-phosphonovaleric acid) to determine the combined AMPAR- and NMDAR-evoked excitatory postsynaptic currents (eEPSCs, at least 10 traces). Subsequently, evoked responses were recorded in the presence of $100 \mu \mathrm{M}$ APV to determine AMPAR eEPSCs (at least 10 traces). The average NMDAR eEPSC amplitude was calculated by subtracting the averaged AMPAR eEPSCs from the averaged combined AMPAR/NMDAR eEPSCs.

Statistical analysis. Results are expressed as mean \pm s.e.m. Statistical analyses were performed using one-way analysis of variance (ANOVA) with repeated measures on the effect of genotype on body weight gain and locomotor activity; two-way ANOVA with repeated measures on escape latencies with genotype and foot shock as main factors and two-way ANOVA without repeated measures on number of failures to escape in the learned helplessness test; two-way ANOVA on corticosterone levels with genotype and restraint stress as main factors and immobility time in the tail suspension and forced swim tests with genotype and drug treatment as main factors; three-way ANOVA on time spent in the social interaction and avoidance zones and social preference ratio in the chronic social defeat paradigm with genotype, defeat and target as main factors. Bonferroni/
Dunn post hoc comparisons followed ANOVAs. Two-tailed Student's $t$-test was used for statistical analysis of the rest of experimental results. $P<0.05$ was considered statistically significant.

\section{Results}

Generation of mice with ablation of the long form of Lepr in forebrain glutamatergic neurons. The ablation of the long form of Lepr was induced by crossing Lepr flox/flox with mice bearing the Emx1-Cre transgene, ${ }^{39}$ which is expressed principally in glutamatergic neurons of the hippocampal formation and dorsal cerebral cortex. ${ }^{35-37}$ Immunohistochemical detection of $\beta$-galactosidase, a readout of cell-specific Emx1-Cre expression, ${ }^{39,40}$ confirmed that Cre expression was restricted to neurons located in the hippocampus and cerebral cortex in Lepr flox/flox, Emx1-Cre/+ (Lepr cKO) (Figure 1a). Reverse transcription-PCR analysis showed that exon 17 of Lepr mRNA was almost abolished in the hippocampus and cortex, but unaltered in the hypothalamus, indicating that Cre-mediated deletion of Lepr in Lepr cKO mice was specific to the hippocampus and cerebral cortex (Figure 1b). Real-time PCR results confirmed the deletion of $>90 \%$ of Lepr in the hippocampus and cortex in Lepr cKO mice (Figure 1c).

General physical and hormonal assessments of Lepr cKO mice. Body weight of Lepr cKO mice and AWT littermate controls were monitored from 4 to 12 weeks of age. Mice exhibited similar body weight gain and showed no genotype difference $\left(\mathrm{F}_{(1,288)}=0.063, P>0.5\right.$ for males; $\mathrm{F}_{(1,280)}=1.100, P>0.1$ for females; Figure 1d). Body composition was analyzed using dual-energy X-ray absorptiometry at 14 weeks of age. Fat mass and lean mass were similar between the two genotypes (males: fat mass $t_{(14)}=$ 0.056, $P>0.5$; lean mass $\mathrm{t}_{(14)}=0.361, P>0.5$. females: fat mass $\mathrm{t}_{(14)}=0.413, P>0.5$; lean mass $\mathrm{t}_{(14)}=0.427, P>0.5$; Figure 1e). These results indicate that growth rate and fat deposition are not altered by deletion of Lepr in forebrain glutamatergic neurons. In consistence with normal body weight and adiposity, plasma levels of leptin and insulin were indistinguishable between the two genotypes $\left(\mathrm{t}_{(8)}=1.068\right.$, $P>0.1$ for leptin; $\mathrm{t}_{(8)}=0.933, P>0.1$ for insulin; Figures $1 \mathrm{f}$ and $\mathrm{g}$ ).

Many tests for depression- and anxiety-related behaviors depend upon proper motor and visual functions. We examined locomotor activity in Lepr cKO mice. No differences in the distance traveled within $30 \mathrm{~min}$ were observed between Lepr cKO mice and AWT littermate controls (males: $F_{(1,266)}=$ 0.587, $P>0.1$ for the time course of the distance traveled every $2 \mathrm{~min} ; \mathrm{t}_{(19)}=0.766, P>0.1$ for the total distance traveled within $30 \mathrm{~min}$; Figure $2 \mathrm{a}$, females: $F_{(1,224)}=0.034$, $P>0.5$ for the time course of distance traveled every $2 \mathrm{~min}$; $\mathrm{t}_{(16)}=0.185, P>0.5$ for the total distance traveled within $30 \mathrm{~min}$; Figure $2 \mathrm{~b}$ ). To examine motor coordination, we performed the rotarod test. LeprcKO and AWT control mice showed similar latencies to fall (males: AWT $164 \pm 23 \mathrm{~s}$, Lepr cKO $172 \pm 27 \mathrm{~s} ; \mathrm{t}_{(18)}=0.224, P>0.5$; females: AWT $152 \pm 18 \mathrm{~s}$, Lepr cKO $\left.130 \pm 16 \mathrm{~s} ; \mathrm{t}_{(36)}=0.883, P>0.1\right)$. These results 
a

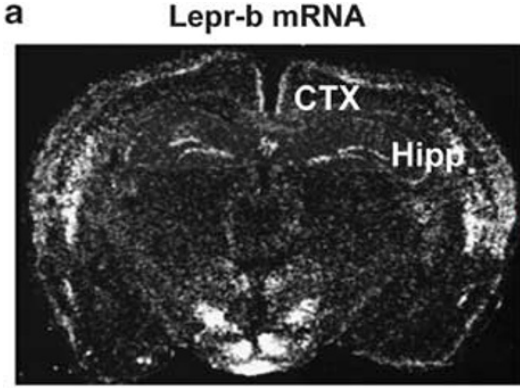

Emx1-Cre
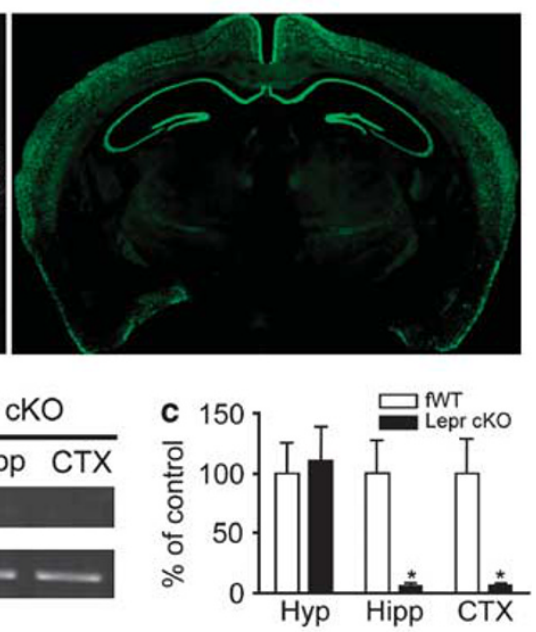

d

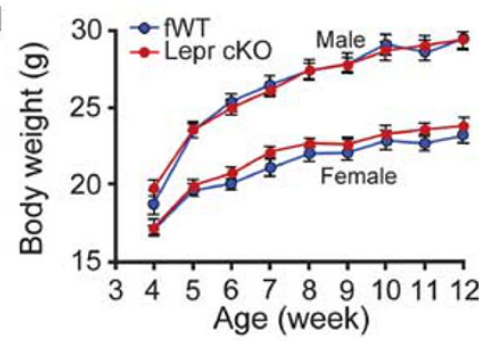

f

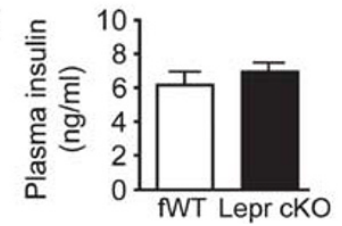

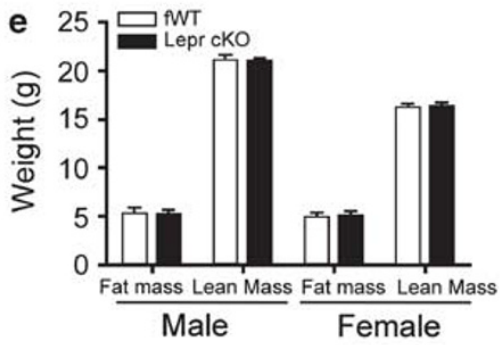

g

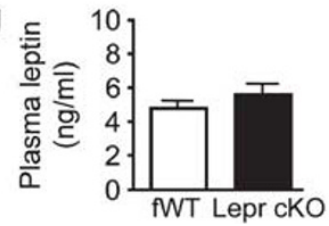

Figure 1 Generation of mice lacking Leprin forebrain neurons. (a, left panel) In situ hybridization showing the long form of Lepr (Lepr-b) mRNA expression. (a, right panel) Fluorescence immunohistochemistry of $\beta$-galactosidase indicating that Cre activity under the control of Emx1 promoter was restricted to the hippocampal and cortical neurons. (b) Reverse transcription-PCR analysis of gene expression of Exon 17 of the leptin receptor in the hippocampus, cortex and hypothalamus. (c) Real-time quantitative PCR analysis of gene expression of Exon 17 of Lepr in the hippocampus, cortex and hypothalamus. ${ }^{*} P<0.05$ compared with $A W T$ controls. (d) Body weight gain of Lepr cKO mice and ANT littermate controls in males and females from 4 to 12 weeks of age. Male ANT, $n=19$; male Lepr cKO, $n=19$; female ANT, $n=17$; female Lepr cKO, $n=20$. (e) Body composition in both male and female mice; $n=8$ per group. (f) Plasma concentrations of leptin; $n=5$ per group. (g) Plasma concentrations of insulin; $n=5$ per group. All data are presented as mean \pm s.e.m.

suggest that Lepr cKO mice have normal locomotor activity and motor coordination. To evaluate visual acuity, we performed the visual cliff test in mice at the age of 13 weeks. The $\mathrm{AWT}$ control mice showed $73 \pm 6.2 \%$ safe responses and Lepr cKO mice exhibited $73 \pm 4.1 \%$ safe responses, suggesting that both genotypes are capable of pattern discrimination and have no gross vision impairments at the age tested.

\section{Behavioral phenotypes of Lepr cKO mice}

Depression-like behaviors. To determine whether inactivation of Lepr in forebrain glutamatergic neurons affects moodrelated behaviors, we performed a series of behavioral tests. The tail suspension test and forced swim test have been widely used to assess 'despair behavior', ${ }^{49,50}$ in which animals are subjected to an inescapable stressful situation and subsequently adopt an immobile posture. The duration of immobility, referred to as 'despair', is attenuated by a variety of antidepressants. ${ }^{51,52}$ Both male and female Lepr cKO mice showed a significantly longer immobility time than AWT littermate controls in the tail suspension test (males: $\mathrm{t}_{(17)}=3.282, P<0.01$; females: $\mathrm{t}_{(15)}=3.129, P<0.01$; Figure $2 \mathrm{c}$ ) and forced swim test (males: $\mathrm{t}_{(19)}=2.18, P<0.05$; females: $\mathrm{t}_{(15)}=6.836, P<0.001$; Figure $2 \mathrm{~d}$ ). The increased immobility in Lepr cKO mice is unlikely due to hypolocomotion because the locomotor activity and motor coordination were normal in Lepr cKO mice.

A core symptom of human depression is anhedonia, or the inability to experience pleasure. The preference for sweet solutions over plain water has been used as a paradigm to measure hedonic response to natural reward in rodents. ${ }^{53}$ Mice were habituated to two drinking bottles in their home cage and then allowed free access to a choice of water and a sweet solution for 4 days. LeprcKO mice showed significantly 

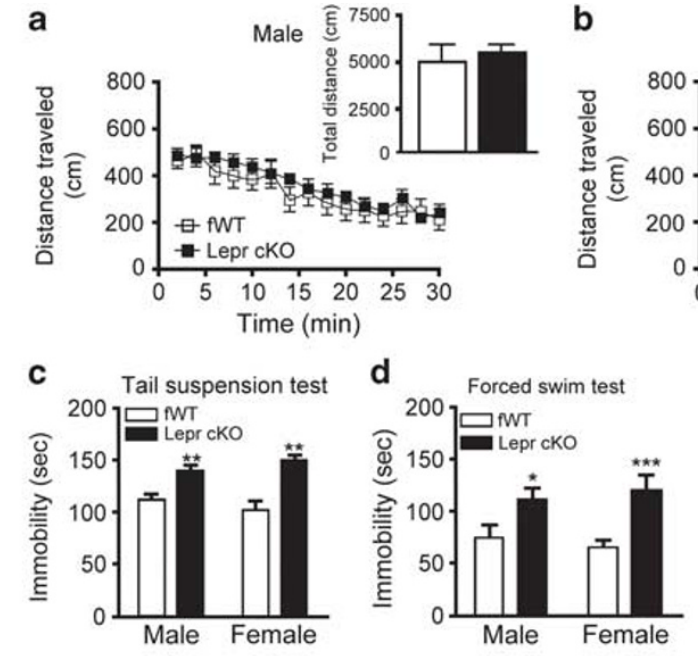

$\mathbf{f}$

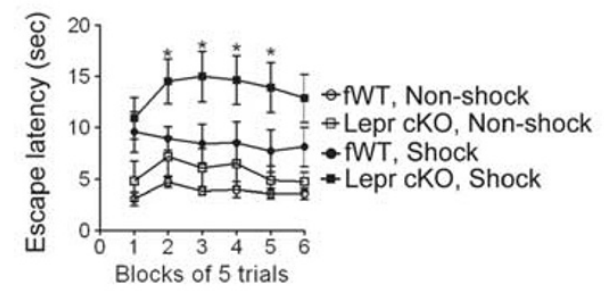

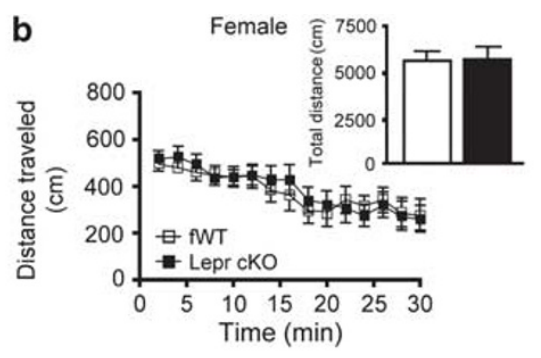

e
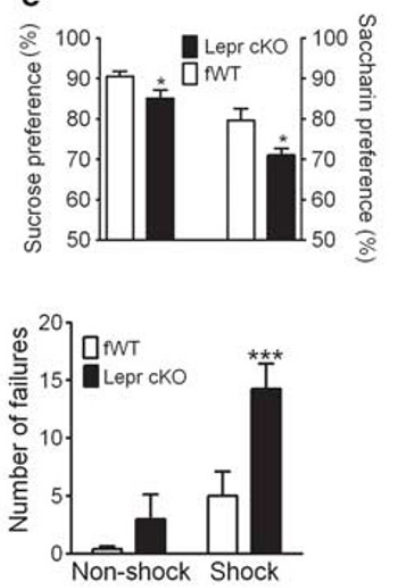

g
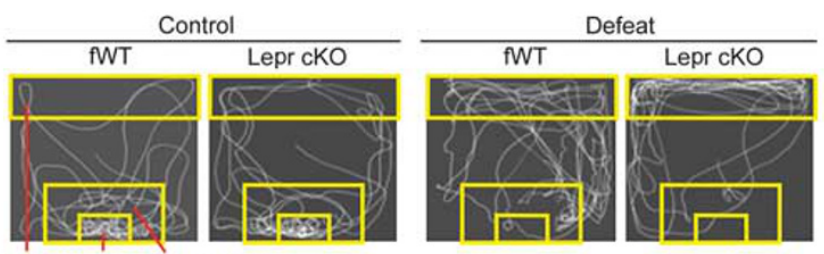

Avoidance Location Interaction

zone of target zone
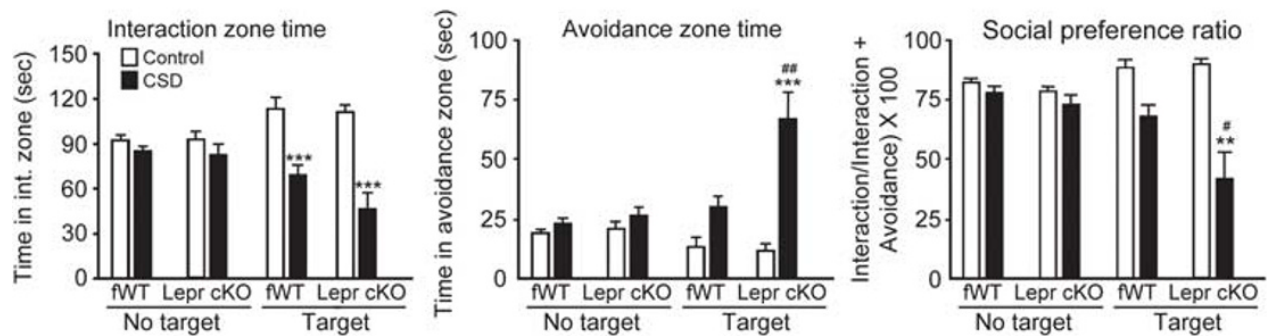

Figure 2 LeprcKO mice exhibit depression-like behaviors. (a, b) Locomotor activity. Locomotor activity was monitored for 30 min and analyzed in 2-min bins. The inserts indicating the total distance traveled during the 30-min test. Male AWT, $n=10$; male LeprcKO, $n=11$; female AWT, $n=8$; female LeprcKO, $n=10$. (c) Tail suspension test. Immobility time was measured during the 6-min test period. Male ANT, $n=8$; male LeprcKO, $n=11$; female AWT, $n=7$; female LeprcKO, $n=10$. ${ }^{*} P<0.01$ compared with the littermate ANT control group. (d) Forced swim test in both males and females. Immobility time was measured during the last 4 min of the 6-min test period. Male AWT, $n=10$; male Lepr cKO, $n=11$; female AWT, $n=8$; female Lepr cKO, $n=9 .{ }^{*} P<0.05,{ }^{* \star *} P<0.001$ compared with the littermate fWT control group. (e) Sweet solution preference tests in males expressed as percent sucrose solution (1\%) or saccharin $(0.01 \%)$ intake within a 4-day test (sucrose or saccharin solution intake/total intake $\times 100$ ). Left $y$ axis, sucrose preference; $n=18$ per group. Right $y$ axis, saccharine preference; $n=9$ for $A \mathrm{NT}, n=10$ for Lepr cKO. ${ }^{*} P<0.05$ compared with the littermate $A \mathrm{NT}$ control group. (f) Learned helplessness test in male mice. (Left panel) Escape latency. (Right panel) Number of failures to escape; $n=10-13$ per group. ${ }^{*} P<0.05$, ${ }^{* \star *} P<0.001$ compared with the AWT, Shock group. (g) Social interaction and avoidance in male mice. (Top) Representative tracks of control (left) or socially defeated (right) fWT or Lepr cKO mice in an arena in the presence of an aggressive CD1 mouse in the target area. (Bottom-left panel) Time spent in the interaction zone. (Bottom-middle panel) Time spent in the avoidance zone. (Bottom-right panel) Social preference ratio defined as time in the interaction zone/(time in the interaction zone + time in the avoidance zone) $\times 100$. $n=8-11$ per group. ${ }^{* *} P<0.01,{ }^{* *} P<0.001$ compared with respective control condition in WT and LeprcKO mice; ${ }^{\#} P<0.05$, ${ }^{\# \#} P<0.01$ compared with defeated $A W T$ mice. All data are expressed as mean \pm s.e.m.

less preference for $1 \%$ sucrose solution than littermate $\mathrm{NWT}$ controls $\left(t_{(34)}=2.198, P<0.05\right.$; Figure $\left.2 e\right)$. To rule out the potential confounding effect of caloric intake in the sucrose preference test, we subsequently tested the mice with $0.01 \%$ saccharin, a noncaloric sweetener. A significant reduction in saccharin preference was observed in Lepr cKO mice 
compared with $\mathrm{ATT}$ littermate controls $\left(\mathrm{t}_{(17)}=2.480, P<0.05\right.$; Figure $2 \mathrm{e})$. These results indicate a hedonic-like phenotype in Lepr cKO mice.

To determine if loss of Lepr in glutamatergic neurons increases the vulnerability to stress-induced depression-like behaviors, Lepr cKO mice were tested using the learned helplessness paradigm. Animals were exposed to inescapable foot shock stress and subsequently tested for a coping deficit in avoidance-escape performance. Escape deficits in this test are sensitive to reversal by antidepressant treatments. ${ }^{54}$ Lepr cKO mice exhibited significant increase in escape latency $\left(F_{(1,215)}=5.020, P<0.05\right)$ and number of escape failure $\left(\mathrm{F}_{(1,43)}=9.031, P<0.01\right.$; Figure $\left.2 \mathrm{f}\right)$. To ensure that the escape deficit of LeprcKO was not due to alteration in pain sensitivity, we performed the hot-plate test to measure the pain reflex threshold of the footpad contacting a heated surface. No difference in hot-plate response latencies was observed between Lepr cKO mice and $\mathrm{WWT}$ littermate controls ( WT 24.4 $\pm 3.5 \mathrm{~s}$, Lepr cKO $24.3 \pm 5.4 \mathrm{~s} ; \mathrm{t}_{(16)}=0.052$, $P>0.5$ ), suggesting that the behavioral changes in the learned helplessness test represent true coping deficits.

Chronic social defeat stress using the resident-intruder paradigm has been validated as an animal model of depression. ${ }^{41,44}$ To determine whether Lepr deletion in glutamatergic neurons confers a vulnerability to stress-induced social avoidance, male Lepr cKO mice and AWT littermate control mice were subjected to social defeat in the home cage of an unfamiliar aggressive CD1 mouse each day for 10 days. Social interaction was examined for two 2.5 -min sessions in the absence or presence of a 'target' CD1 mouse, respectively, at $24 \mathrm{~h}$ after the last session of social defeat (Figure $2 \mathrm{~g}$ ). ANOVA analyses showed significant effects of social defeat on the time spent in the interaction zone $\left(F_{(1,64)}=43.301\right.$, $P<0.001)$ and the avoidance zone $\left(F_{(1,64)}=25.738\right.$, $P<0.001)$ and on social preference ratio $\left(F_{(1,64)}=30.388\right.$, $P<0.001)$ and significant effects of genotype on the time spent in the avoidance zone $\left(\mathrm{F}_{(1,64)}=5.772, P<0.05\right)$ and social preference ratio $\left(\mathrm{F}_{(1,64)}=4.605, P<0.05\right)$. There were significant defeat $\times$ genotype interactions observed on time spent in the avoidance zone $\left(\mathrm{F}_{(1,64)}=5.228, P<0.05\right)$ and social preference ratio $\left(\mathrm{F}_{(1,64)}=4.172, P<0.05\right)$. Post hoc comparisons indicated that time spent in the avoidance zone was increased and social preference ratio was decreased in Lepr cKO mice compared with $\mathrm{WT}$ littermate controls during the presence of a 'target' CD1 mouse (Figure 2g). This suggests that loss of Lepr in forebrain glutamatergic neurons enhances stress-induced social aversion.

Anxiety-like behaviors. To assess whether depression-like behaviors in Lepr cKO mice are accompanied by anxiety-like behaviors, we performed three behavioral tests to evaluate anxiety levels: the EPM, the open-field test and the light/dark choice. In the EPM, reduced time spent in the open arms and numbers of entries made into the open arms within the $5 \mathrm{~min}$ test are taken as indices of anxiety. There were no differences in time spent in the open arms (males: $t_{(16)}=0.270$, $P>0.5$; females: $\left.\mathrm{t}_{(14)}=0.260, P>0.5\right)$ or entries into the open arms (males: $\mathrm{t}_{(16)}=0.371, P>0.5$; females: $\mathrm{t}_{(14)}=$ 0.182, $P>0.5$ ) between Lepr cKO and AWT mice (Supplementary Figure S1A). When placed in an open field arena, anxious mice tend to spend less time in the center and more time in the corners. Lepr cKO and AWT mice spent similar amounts of time in the central zone (males: $t_{(18)}=$ $0.182, P>0.5$; females: $\left.\mathrm{t}_{(15)}=0.870, P>0.1\right)$ and traveled similar total distances within the arena (males: $\mathrm{t}_{(18)}=0.003$, $P>0.5$; females: $\mathrm{t}_{(15)}=1.936 ; \quad P>0.05 ;$ Supplementary Figure S1B). In the light/dark choice test, there were no differences in the amount of time spent in the light box (males: $\mathrm{t}_{(15)}=0.338, P>0.5$; females: $\mathrm{t}_{(23)}=1.007, P>0.1$ ) or the total number of transitions between light and dark boxes (males: $\mathrm{t}_{(15)}=0.682, P>0.5$; females: $\mathrm{t}_{(23)}=0.796$, $P>0.1$; Supplementary Figure S1C). Collectively, these tests demonstrate that anxiety-like behaviors are not affected by loss of Lepr in forebrain glutamatergic neurons.

Hypothalamic-pituitary-adrenal (HPA) axis activity in Lepr cKO mice. The HPA axis hyperactivity is an important mechanism in the pathogenesis of depression. ${ }^{55,56}$ The HPA axis activity is under the negative control of hippocampus. ${ }^{57,58}$ Therefore, we determined whether deletion of Lepr in forebrain glutamatergic neurons would affect HPA axis activity. First, we measured glucocorticoid receptor mRNA in the hippocampus using semiquantitative in situ hybridization. The levels of glucocorticoid receptor mRNA in CA1, CA3 and dentate gyrus of the hippocampus were indistinguishable between Lepr cKO mice and AWT littermate controls (CA1 $\mathrm{t}_{(6)}=0.007, P>0.5 ;$ CA3 $\mathrm{t}_{(6)}=0.881, P>0.1$; dentate gyrus $\mathrm{t}_{(6)}=1.151, P>0.1$; Figure 3a). Second, corticotropinreleasing hormone mRNA expression in the paraventricular nucleus of the hypothalamus was examined and showed no difference between the two genotypes $\left(\mathrm{t}_{(6)}=1.723, P>0.1\right.$; Figure $3 b)$. Moreover, plasma levels of corticosterone were determined under basal and stressed conditions. Lepr cKO mice displayed a normal diurnal rhythm in plasma corticosterone concentrations as compared with AWT mice $\left(\mathrm{t}_{(8)}=0.357 ; P>0.5\right.$ for the morning and $\mathrm{t}_{(10)}=0.267$; $P>0.5$ for the afternoon; Figure $3 c)$. The responsiveness of corticosterone to stress was determined by subjecting animals to $30 \mathrm{~min}$ restraint stress. ANOVA showed significant effect of stress $\left(\mathrm{F}_{(2,26)}=275.728 ; P<0.001\right)$ but not genotype $\left(\mathrm{F}_{(1,26)}=2.785 ; P>0.1\right)$ or stress $\times$ genotype interaction $\left(\mathrm{F}_{(2,26)}=1.472 ; P>0.1\right)$ on corticosterone levels. Restraint stress-induced elevation of corticosterone levels were similar between the two genotypes (Figure 3d). These results indicate that Lepr cKO mice have normal HPA axis function.

Hippocampal synaptic plasticity in Lepr cKO mice. Neuroplasticity has been proposed as a mechanism underlying the development of major depressive disorder. ${ }^{59,60}$ Abnormal hippocampal synaptic plasticity has been observed in chronic mild stress, an animal model of depression, and antidepressants can reverse this effect. ${ }^{61-63}$ To determine whether hippocampal synaptic plasticity is affected in Lepr cKO mice, we performed systematic analysis of synaptic functions in the hippocampus. The fEPSPs were recorded at CA3-CA1 Schaeffer collateral synapses in hippocampal slices derived from adult Lepr cKO and AWT mice (8-12 weeks). Initial characterization of Lepr cKO slices revealed no obvious deficits in the basic properties of CA1 synapses. 
a

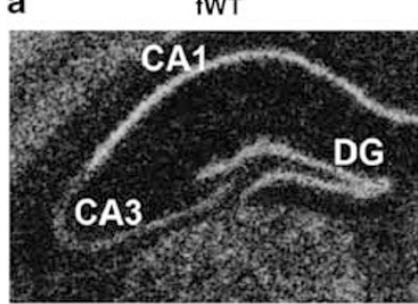

b

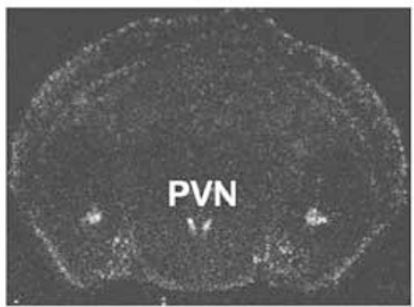

C

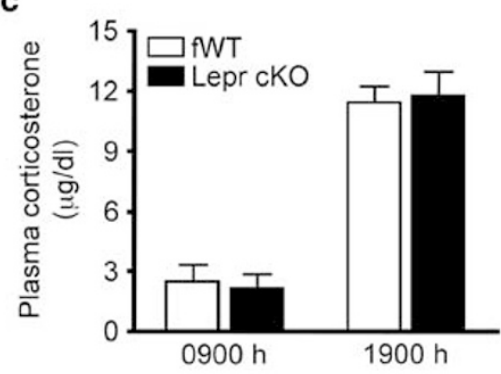

Lepr cKO
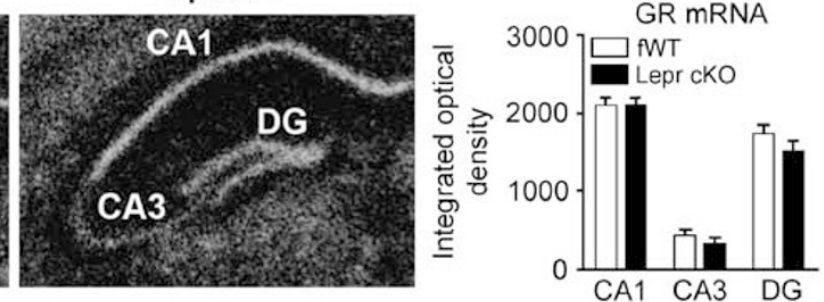
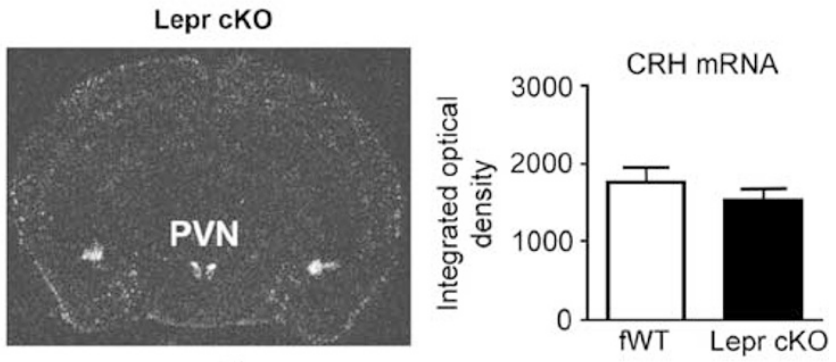

d

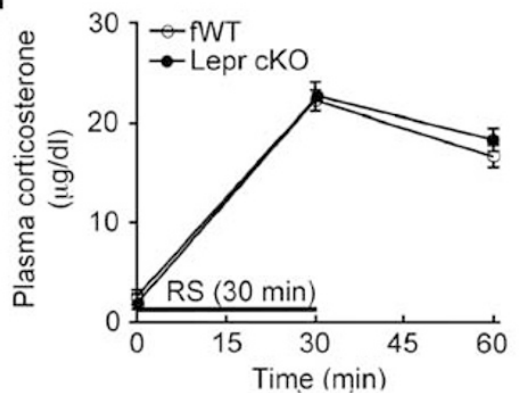

Figure 3 The hypothalamic-pituitary-adrenal (HPA) axis activity in Lepr cKO mice. (a) Glucocorticoid receptor (GR) mRNA expression in the hippocampus. (Left panel) Representative autoradiograms showing GR mRNA expression in coronal brain sections from AWT and LeprcKO mice. (Right panel) Quantitative data indicating relative levels of GR mRNA in the hippocampus; $n=4$ per group. DG, dentate gyrus. (b) Corticotropin-releasing hormone (CRH) mRNA expression in the paraventricular nucleus of hypothalamus (PVN). (Left panel) Representative autoradiograms showing CRH mRNA expression in coronal brain sections from ANT and Lepr cKO mice. (Right panel) Quantitative data indicating relative levels of $\mathrm{CRH}$ mRNA in the PVN; $n=4$ per group. (c) Baseline corticosterone levels in plasma, measured in the early morning (0900 $\mathrm{h}, 2 \mathrm{~h}$ after light on) and in the late afternoon ( $1900 \mathrm{~h}, 2 \mathrm{~h}$ before light off). (d) Stress-induced corticosterone secretion. Trunk blood samples were collected after rapid decapitation. Plasma corticosterone levels were measured before exposure to restraint stress (RS), at the end of 30 min restraint and 30 min after the cessation of restraint stress; $n=5-6$ per group. All data are presented as mean \pm s.e.m.

A high-frequency, tetanic stimulation train $(100 \mathrm{~Hz}, 1 \mathrm{~s})$ was used to induce LTP. The high-frequency stimulation produced almost identical LTP in Lepr cKO and AWT mice (fWT: $152 \pm 8 \%$; Lepr cKO: $152 \pm 9 \%$, measured 55-60 min after tetanus; Figure 4a). Induction of LTD by low-frequency stimulation (LFS; $15 \mathrm{~min}, 1 \mathrm{~Hz}$ ) was examined in adult hippocampal slices. LFS failed to induce LTD in AWT control mice $(95 \pm 2 \%$ at $70-75 \mathrm{~min}$, Figure $4 \mathrm{~b})$. This is not surprising because LFS-induced LTD is age dependent and is observed in juvenile but not adult wild-type mice. ${ }^{64-66}$ LFS also did not induce LTD in Lepr cKO mice (Figure 4b). The fEPSP slope recorded at 70-75 min after the onset of LFS was $99 \pm 5 \%$ of the baseline recorded before the application of LFS. The input-output curves in Lepr cKO and AWT were virtually indistinguishable (Figure 4c), suggesting that deletion of Lepr in glutamatergic neurons does not affect basal synaptic transmission. Similarly, there was no difference in paired-pulse facilitation, a measure of presynaptic release probability, over the whole range of interstimulus intervals between the two groups (Figure 4d).
The standard LFS-induced plasticity only accesses a fraction of available synapses. LTD can also be induced chemically by a brief application of NMDA to the hippocampal slices, ${ }^{67,68}$ which activates synaptic as well as extrasynaptic NMDA receptors. ${ }^{69}$ Application of NMDA for 7 min resulted in a transient depression of synaptic efficacy that almost returned to baseline within $<30 \mathrm{~min}$ in AWT control slices (Figure 5a). Surprisingly, the same NMDA perfusion induced a robust LTD in Lepr cKO slices (Figure 5a). At least two possible mechanisms may underlie the enhancement of NMDA-induced LTD. First, a deficit in the developmental switch from GluN2B to GluN2A (NR2A) may result in CA1 synapses containing more GluN2B, which has much slower decay time and is implicated in LTD. However, whole-cell recording of evoked synaptic currents indicated that the ratio of NMDAR/AMPAR currents was unaltered in Lepr cKO synapses (Supplementary Figure S2A). This, together with the finding that basal synaptic transmission is normal in Lepr cKO slices (Figure 4c), indicates that synaptic NMDAR activity is not grossly elevated in the synapses of Lepr cKO to cause 
a1
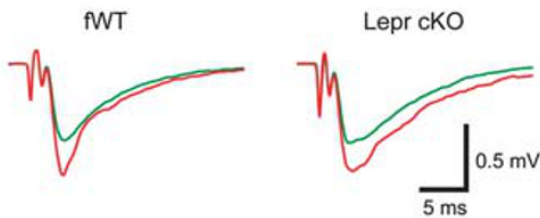

a2
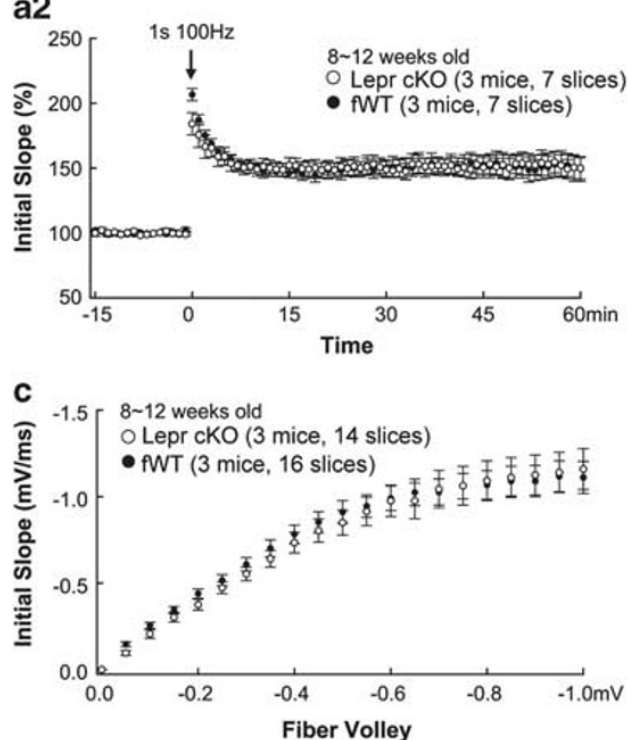

b1

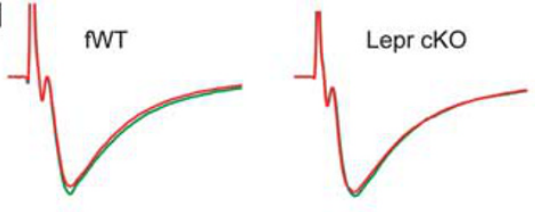

b2

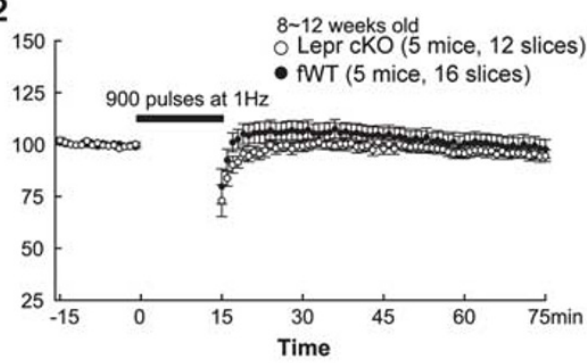

d

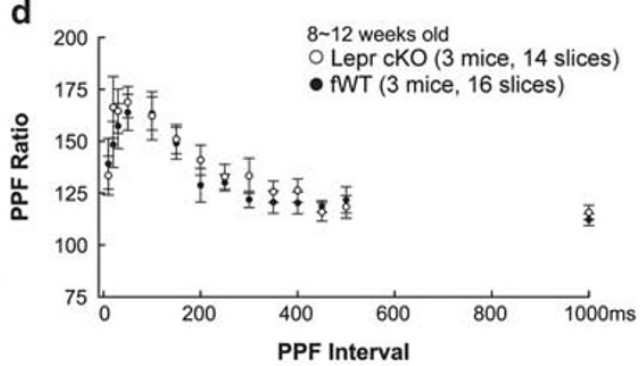

Figure 4 Long-term potentiation (LTP) and long-term depression (LTD) in adult LeprcKO mice. (a) LTP was induced by a single tetanus (1 s per $100 \mathrm{~Hz})$ in CA1 of acute hippocampal slices from LeprcKO and littermate-matched AWT control mice. LTP is comparable in hippocampal slices from Lepr cKO and littermate-matched fWT control mice (open and closed circles, respectively). Examples of field excitatory postsynaptic potential (fEPSP) recordings before (green lines) and 60 min after LTP (a1) induction (red lines) are shown in the upper panels. (b) LTD was absent in both Lepr cKO and fWT mice with the stimulation of a single train of 900 pulses at $1 \mathrm{~Hz}$. Examples of fEPSP recordings before (green lines) and 60 min after LTD (b1) induction (red lines) are shown in the upper panels. (c) Input-output curves with the postsynaptic response (initial slope of fEPSP) plotted as a function of the presynaptic fiber volley amplitude is indistinguishable between Lepr cKO mice and AWT control mice. (d) Paired-pulse facilitation (PPF) is virtually identical for LeprcKO and AWT control mice over the whole range of interstimulus intervals. Data are presented as mean \pm s.e.m. The group sizes are given in each graph.

enhanced LTD. Furthermore, the decay time of NMDA currents at AWT and Lepr cKO synapses was quite similar, suggesting that GluN2B/GluN2A ratio is not dramatically increased at the synapses of Lepr cKO mice (Supplementary Figure S2B). Thus, a deficit in the developmental switch from GluN2A to GluN2B is less likely. The second possibility is that Lepr deletion results in an increase in extrasynaptic NMDAR activity. To test this, LTD-inducing protocol was applied in the presence of PDC (a glutamate transporter inhibitor), which reduces glutamate uptake at the synaptic cleft and therefore increases glutamate spillover to extrasynaptic sites to activate extrasynaptic NMDAR. If NMDA-induced LTD is truly because of extrasynaptic NMDAR, LFS should now be able to induce LTD in adult CA1 synapses. Indeed, a mild LTD was observed $75 \mathrm{~min}$ after $1 \mathrm{~Hz}$ stimulation in the AWT control slices. Remarkably, LeprcKO exhibited a much greater LFS-induced LTD (Figure 5b). Thus, the facilitation of NMDA-induced LTD in Lepr cKO mice is likely mediated by an increase in extrasynaptic NMDAR activity. Because extrasynaptic NMDA receptors contain mostly GluN2B subunits, ${ }^{70}$ we therefore examined the role of GluN2B in LFS-induced LTD. The application of the GluN2B antagonist ifenprodil completely blocked LTD in Lepr cKO mice induced by LFS in the presence of PDC (Figure 5c).

Behavioral responses of Lepr cKO mice to leptin and an GluN2B antagonist. To determine whether Lepr in forebrain glutamatergic neurons mediates the antidepressant-like effects of leptin, we tested the behavioral responses of Lepr cKO mice to leptin. As described previously, ${ }^{21}$ mice received injection of leptin $\left(1.0 \mathrm{mg} \mathrm{kg}^{-1}\right.$, intraperitoneal) or saline and subjected to the tail suspension test or forced swim test at $30 \mathrm{~min}$ after intraperitoneal injection. ANOVA showed significant effects of genotype $\left(F_{(1,44)}=18.000 ; P<0.001\right)$, drug treatment $\left(F_{(2,44)}=28.811 ; P<0.001\right)$ and interaction between genotype and drug treatment $\left(F_{(2,44)}=12.653 ; P<0.001\right)$ on tail suspension test. Similar results were found in forced swim test as significant effects of genotype $\left(F_{(1,51)}=8.181\right.$; $P<0.01)$, drug treatment $\left(F_{(2,51)}=18.277 ; P<0.001\right)$ and interaction between genotype and drug treatment $\left(F_{(2,51)}=\right.$ 3.383; $P<0.05)$. Post hoc analysis demonstrated that Lepr cKO mice treated with saline exhibited increased immobility compared with AWT littermate control mice treated with saline in both behavioral tests (Figures $6 a$ and b). Although leptin 
a1

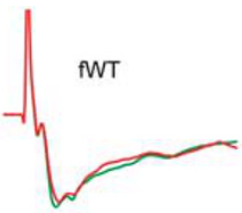

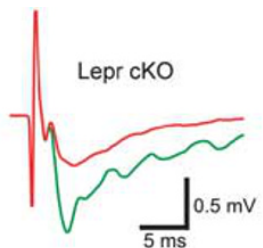

a2

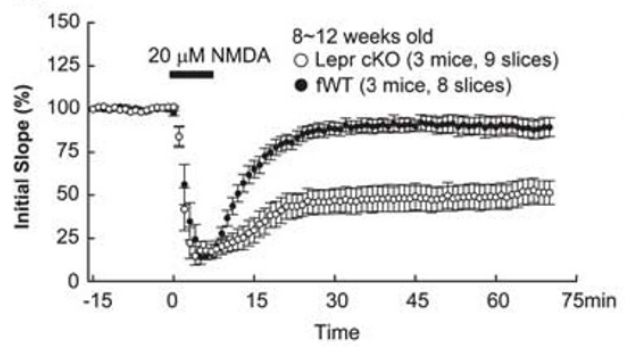

b1

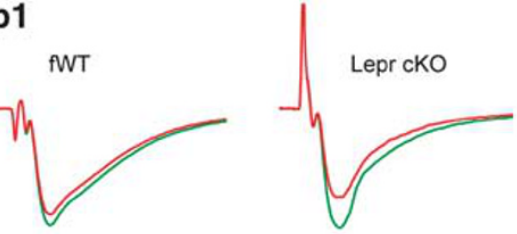

b2

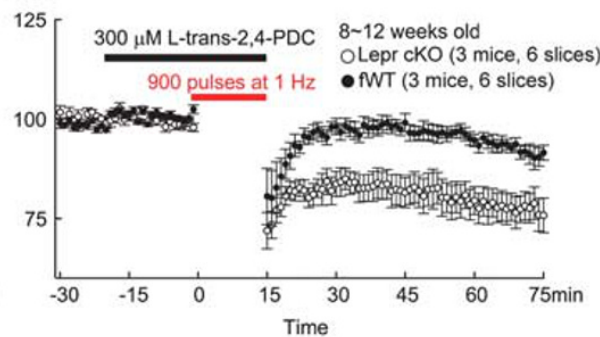

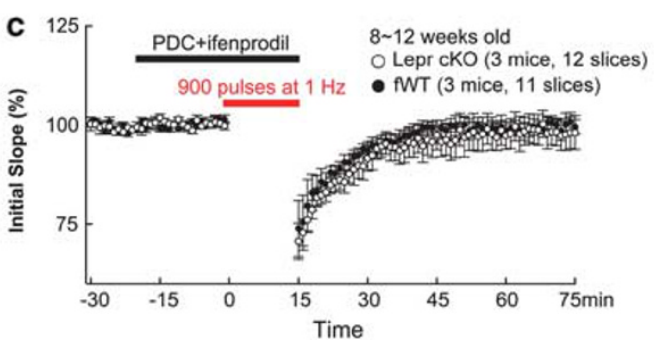

Figure 5 The N-methyl-D-aspartate (NMDA)-induced long-term depression (LTD) is facilitated in adult Lepr cKO mice. (a) LTD induced with bath application of $20 \mu \mathrm{M}$ NMDA for $7 \mathrm{~min}$ is significantly increased in Lepr cKO mice compared with AWT mice (open and closed circles, respectively, $P<0.005$ ). Examples of field excitatory postsynaptic potential (fEPSP) recordings before (green lines) and $60 \mathrm{~min}$ after LTD induction (red lines) are shown in panel a1. (b) LTD induced by the stimulation of a single train of 900 pulses at $1 \mathrm{~Hz}$ with bath application of $300 \mu \mathrm{M} \mathrm{L-trans-pyrrolidine-2,4-dicarboxylic} \mathrm{acid} \mathrm{(PDC)} \mathrm{is} \mathrm{significantly} \mathrm{increased} \mathrm{in} \mathrm{Lepr} \mathrm{cKO} \mathrm{mice} \mathrm{compared} \mathrm{with} \mathrm{AWT}$ mice (open and closed circles, respectively, $P<0.01$ ). Examples of fEPSP recordings before (green lines) and 60 min after LTD induction (red lines) are shown in panel b1. (c) LTD induced by the stimulation of a single train of 900 pulses at $1 \mathrm{~Hz}$ with bath application of $300 \mu \mathrm{M} \mathrm{L-trans-2,4-PDC}$ is completely blocked by GluN2B antagonist ifenprodil in Lepr KO mice compared with ANT mice (98 \pm 5 vs $100 \pm 4 \%$ at 70-75 min, open and closed circles, respectively). Data are presented as mean \pm s.e.m. The group sizes are given in each graph.

a

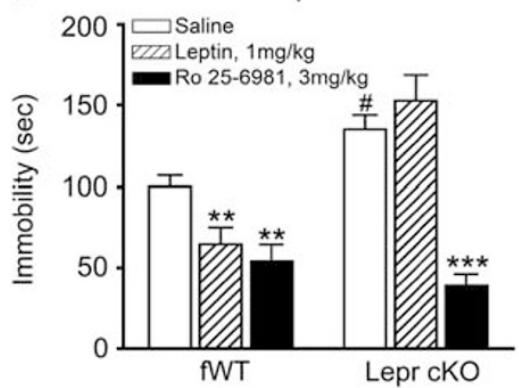

b

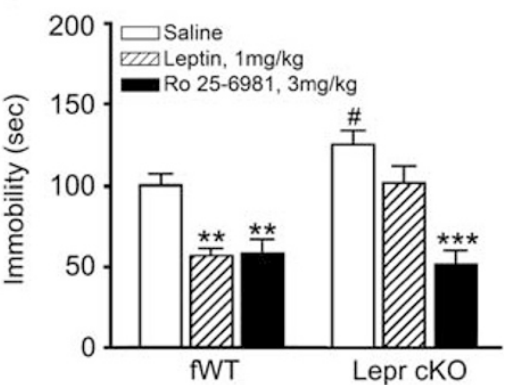

Figure 6 Behavioral responses of Lepr cKO mice to leptin and GluN2B antagonist. (a) Tail suspension test. Leptin (1 $\left.\mathrm{mg} \mathrm{kg}^{-1}\right)$, selective GluN2B antagonist Ro25-6981 $\left(3 \mathrm{mg} \mathrm{kg}^{-1}\right)$ or saline were intraperitoneally (i.p.) administered to mice $30 \mathrm{~min}$ before the test. Immobility time was measured during the 6 -min test period. Data are presented as mean \pm s.e.m; $n=8-9$ per group. ${ }^{\#} P<0.05$ compared with saline-treated AWT group, ${ }^{\star \star} P<0.01$, ${ }^{\star \star \star} P<0.001$ compared with saline treatment within the same genotype. (b) Forced swim test. Mice were treated as described in panel a. Immobility time was measured during the last 4 min of the 6-min test period. Data are presented as mean \pm s.e.m; $n=7-13$ per group. ${ }^{\#} P<0.05$ compared with saline-treated fWT group, ${ }^{* *} P<0.01,{ }^{* * *} P<0.001$ compared with saline treatment within the same genotype.

significantly decreased 'behavioral despair' in AWT littermate controls, this effect was abolished by deletion of Lepr in forebrain glutamatergic neurons in Lepr cKO mice (Figures 6a and b).

Selective GluN2B antagonists produce antidepressant actions similar to ketamine in both animal models and humans. ${ }^{14,20}$ We examined whether Lepr cKO mice respond to antidepressant effects induced by blocking GluN2B. Mice were administered the selective GluN2B antagonist Ro256981 (3.0 $\mathrm{mg} \mathrm{kg}^{-1}$, intraperitoneal) and tested as described above. Post hoc analysis demonstrated that Ro25-6981 treatment induced a greater reduction of 'behavioral despair' 
in Lepr cKO mice than $\mathrm{WTT}$ littermate controls in the tail suspension test $(71 \%$ for Lepr cKO mice versus $46 \%$ for AWT littermate controls), eliminating the difference in 'behavioral despair' between the two genotypes (Figure 6a). Similar findings were obtained from the forced swim test $(63 \%$ decrease in immobility for Lepr cKO mice versus $42 \%$ for AWT littermate controls; Figure 6b). These results suggest that Ro25-6981 can reverse the increased 'behavioral despair' in depressive Lepr cKO mice. Together, these findings suggest that the leptin receptor on forebrain glutamatergic neurons is required for the antidepressant-like behavioral effect of leptin, and the GluN2B antagonist has antidepressant efficacy in mice resistant to leptin.

\section{Discussion}

There are several interesting findings in this study. First, selective ablation of the long form of Lepr in forebrain glutamatergic neurons located in the hippocampus and dorsal cerebral cortex leads to depression-related behaviors. Second, NMDA-induced hippocampal LTD is facilitated in mice lacking Lepr in forebrain glutamatergic neurons, which is mediated by GluN2B-containing NMDA receptors. Third, these mice are sensitive to the antidepressant-like behavioral effects of the GluN2B antagonist but resistant to leptin. These findings provide strong evidence for a critical role of Lepr signaling in forebrain glutamatergic neurons in regulating depression-related behaviors and suggest a functional relationship between Lepr signaling and NMDA receptors in modulating depression-related behaviors and induction of long-term synaptic depression.

Depression is a complex disorder characterized by complex patterns of symptoms. We assessed behavioral phenotypes of Lepr cKO mice using a battery of tests that detect different aspects of depression, including anhedonia, behavioral despair, learned helplessness and social withdrawal. Under basal conditions, loss of Lepr in forebrain glutamatergic neurons caused an anhedonia-like phenotype in the sucrose/ saccharin preference tests. Also, Lepr cKO mice displayed behavioral despair in the tail suspension and forced swim tests. Stress is a key environmental factor that can trigger the onset of depression in genetically vulnerable individuals. Increased susceptibility to stress-induced depressive behaviors was observed in Lepr cKO mice as evidenced by increased escape latency and number of failures to escape following exposure to inescapable foot shock and enhanced social avoidance after exposure to chronic social defeat. These findings suggest that defects in Lepr signaling in forebrain glutamatergic neurons may be a predisposition that interacts with stress to increase vulnerability for depression. Locomotor activity and visual functions were not affected in Lepr cKO mice, suggesting that the depression-like behavioral deficits in these mice cannot be attributed to motor or sensory impairments. We have previously shown that leptin produces antidepressant-like effects in rats and mice, ${ }^{21,22}$ and this finding has been recently confirmed by another research group. ${ }^{23}$ However, it remained unclear what neuronal populations mediate leptin's antidepressant-like effects. In the present study, we demonstrated that loss of Lepr in glutamatergic neurons in the hippocampus and cortex abolished the antidepressant-like behavioral effect of leptin in both the forced swim test and the tail suspension test. These results suggest that glutamatergic neurons in the dorsal forebrain regions are targets for leptin's action on depressive-like behaviors. Although depression often coexists with anxiety, there were no evident signs of anxiety observed in LeprcKO mice as assessed in multiple behavioral tests including the EPM, light/dark choice and open-field tests. Our recent studies have shown that mice with selective ablation of Lepr in midbrain dopamine neurons display anxiogenic-like behaviors without affecting depression-like behaviors. ${ }^{45}$ Taken together, these findings suggest that leptin action on depression- and anxiety-related behaviors are mediated by distinct neuronal circuits.

Increasing evidence points to a link between impairments of plasticity at glutamatergic synapses and depression. LTP and LTD are two major forms of persistent synaptic plasticity in the central nervous system characterized by a long-lasting increase or decrease in synaptic strength, respectively. Stress, including chronic unpredictable stress, an animal model of depression, has been shown to impair LTP and facilitate LTD in the adult hippocampus, ${ }^{61,71-73}$ and the effects of stress on synaptic plasticity can be blocked by treatment with antidepressants. ${ }^{61,74}$ Previous pharmacological studies have reported that leptin regulates hippocampal long-term synaptic plasticity. However, the results from these studies are inconsistent. Both enhancement and inhibition of hippocampal LTP in response to leptin treatment have been reported, ${ }^{75-77}$ often depending on the dosage of leptin used or the age of animals. In mice and rats with naturally occurring loss-of-function mutations in Lepr ( $d b / d b$, fa/fa), both LTP and LTD are impaired. ${ }^{78-80}$ However, these animals are morbidly obese and diabetic with hyperinsulinemia and hypercorticosteronemia. ${ }^{81-83}$ Both insulin and corticosterone have been shown to modulate LTP and LTD. ${ }^{84-90}$ Thus, one cannot rule out the possibility that abnormally high levels of insulin and corticosterone contribute to the disrupted LTP and LTD induction observed in $d b / d b$ mice and fa/fa rats. In this study, mice with ablation of Leprselectively in forebrain glutamatergic neurons had normal body weight and normal insulin and corticosterone levels. Standard electric stimulus-induced LTP or LTD was not affected in these mice, but they displayed a robust enhancement of chemically (NMDA)-induced LTD in adult hippocampus. This could result from a deficit in the developmental switch from GluN2B- to GluN2A-containing receptors at synapses. However, this possibility is not supported by the data presented here as synaptic NMDAR activity and GluN2B/ GluN2A ratio were not significantly elevated at the synapses of Lepr cKO mice. Another possibility is that increased extrasynaptic NMDAR activity causes LTD in Lepr cKO mice. Inhibiting the synaptic glutamate transporter facilitates spillover of glutamate to extrasynaptic sites. We found that the treatment with PDC, a glutamate transporter inhibitor, dramatically increased low-frequency electrical stimulationinduced LTD in Lepr cKO mice. Thus, activation of extrasynaptic NMDA receptors by glutamate spillover in Lepr cKO mice is likely responsible for the induction of LTD. NMDA receptor GluN2B subunits are localized predominantly at extrasynaptic sites. ${ }^{70}$ We found that selective blockade of NMDA receptors containing the GluN2B subunit by ifen- 
prodil prevented the induction of LTD, suggesting that facilitation of LTD induction in Lepr cKO requires GluN2B, possibly by elevating expression or signaling of extrasynaptic GluN2B.

NMDA receptor antagonists, such as ketamine, exert rapid and robust antidepressant effects in some patients with major depression. ${ }^{6,17,18}$ Selective GluN2B antagonists have been used to treat patients with treatment-resistant depression. ${ }^{20}$ In animal studies, the nonselective NMDA antagonist ketamine and the GluN2B-specific antagonist Ro25-6981 have been shown to reverse behavioral despair and learned helplessness. ${ }^{12,14}$ In this study, we demonstrated that Lepr cKO mice were highly sensitive to the antidepressant-like behavioral effects of the GluN2B antagonist Ro25-6981 in both the tail suspension test and the forced swim test, whereas leptin failed to show the antidepressant-like behavioral effects in these mutant mice. These findings suggest that glutamatergic neurons in the forebrain region are target neurons mediating the antidepressant-like effect of leptin and that GluN2B signaling lies downstream of Lepr signaling in regulating depression-related behaviors. The reversal of hippocampal LTD induction and behavioral despair by GluN2B antagonists in Lepr cKO mice imply a link between induction of persistent synaptic depression and behavioral manifestation of depression. However, further investigations are required to better understand this association. Whether a blockade of a specific form of synaptic plasticity could prevent or reverse behavioral depression remains to be determined. It is noteworthy to point out that although LTD has been implicated in hippocampusdependent learning and memory, ${ }^{91-95}$ Lepr cKO mice exhibited normal performance in hippocampus-dependent learning and memory tests including spatial and reversal learning in the Morris water maze, T-maze alternation and contextual fear conditioning (data not shown).

Recent epidemiological studies indicate that obesity, a state reflecting leptin resistance in most obese subjects, increases the incidence of depression. ${ }^{96-100}$ Diet-induced obese mice display depression-like behaviors ${ }^{23,101}$ and are resistant to antidepressant-like behavioral effects of leptin. ${ }^{23}$ However, the question remains whether depression in obese individuals occurs secondary to metabolic changes or as a direct consequence of leptin resistance in the limbic circuitry. Although global loss or neuron-specific loss of leptin signaling (defects in leptin or its receptor) in mice and humans leads to severe obesity, ${ }^{83,102-110}$ ablation of Lepr in forebrain glutamatergic neurons had no effect on body weight, adiposity and hormone levels under basal chow-fed conditions. Thus, the development of depression-like behaviors observed in LeprcKO mice reflects a direct effect of resistance to leptin's action. Recent studies have suggested a U-shaped trend in the association between depression and body mass; both underweight and obesity are associated with depression. ${ }^{111-113}$ We speculate that low leptin levels in underweight individuals and leptin resistance in obese people may contribute to the high prevalence of depression among these populations.

\section{Conflict of interest}

The authors declare no conflict of interest.
Acknowledgements. This work was supported by the NIH Grants NIMH 076929 and NIMH 073844 (to X-YL), the NRSA predoctoral fellowship award NIMH 83442 (to JCG) and funds from intramural research programs of the NICHD and $\mathrm{NIMH}$ (to BL).

1. Kessler RC, Berglund P, Demler O, Jin R, Koretz D, Merikangas KR et al. The epidemiology of major depressive disorder: results from the National Comorbidity Survey Replication (NCS-R). JAMA 2003; 289: 3095-3105.

2. Mitchell AJ, Chan M, Bhatti $H$, Halton M, Grassi L, Johansen $C$ et al. Prevalence of depression, anxiety, and adjustment disorder in oncological, haematological, and palliative-care settings: a meta-analysis of 94 interview-based studies. Lancet Oncol 2011; 12: 160-174.

3. Wong ML, Licinio J. Research and treatment approaches to depression. Nat Rev Neurosci 2001; 2: 343-351.

4. Hashimoto K. Emerging role of glutamate in the pathophysiology of major depressive disorder. Brain Res Rev 2009; 61: 105-123.

5. Maeng S, Zarate Jr CA. The role of glutamate in mood disorders: results from the ketamine in major depression study and the presumed cellular mechanism underlying its antidepressant effects. Curr Psychiatry Rep 2007; 9: 467-474.

6. Sanacora G, Zarate CA, Krystal JH, Manji HK. Targeting the glutamatergic system to develop novel, improved therapeutics for mood disorders. Nat Rev Drug Discov 2008; 7: 426-437.

7. Skolnick P, Popik P, Trullas R. Glutamate-based antidepressants: 20 years on. Trends Pharmacol Sci 2009; 30: 563-569.

8. Machado-Vieira R, Salvadore G, Luckenbaugh DA, Manji HK, Zarate Jr CA. Rapid onset of antidepressant action: a new paradigm in the research and treatment of major depressive disorder. J Clin Psychiatry 2008; 69: 946-958.

9. Chaturvedi HK, Chandra D, Bapna JS. Interaction between N-methyl-D-aspartate receptor antagonists and imipramine in shock-induced depression. Indian J Exp Biol 1999; 37: 952-958.

10. Yilmaz A, Schulz D, Aksoy A, Canbeyli R. Prolonged effect of an anesthetic dose of ketamine on behavioral despair. Pharmacol Biochem Behav 2002; 71: 341-344.

11. Autry $\mathrm{AE}$, Adachi M, Nosyreva $\mathrm{E}, \mathrm{Na} \mathrm{ES}$, Los MF, Cheng PF et al. NMDA receptor blockade at rest triggers rapid behavioural antidepressant responses. Nature 2011; 475 : 91-95.

12. Li N, Lee B, Liu RJ, Banasr M, Dwyer JM, Iwata M et al. mTOR-dependent synapse formation underlies the rapid antidepressant effects of NMDA antagonists. Science 2010; 329: 959-964.

13. Li N, Liu RJ, Dwyer JM, Banasr M, Lee B, Son $\mathrm{H}$ et al. Glutamate N-methyl-D-aspartate receptor antagonists rapidly reverse behavioral and synaptic deficits caused by chronic stress exposure. Biol Psychiatry 2011; 69: 754-761.

14. Maeng S, Zarate Jr CA, Du J, Schloesser RJ, McCammon J, Chen G et al. Cellular mechanisms underlying the antidepressant effects of ketamine: role of alpha-amino-3hydroxy-5-methylisoxazole-4-propionic acid receptors. Biol Psychiatry 2008; 63: 349-352.

15. Trullas R, Skolnick P. Functional antagonists at the NMDA receptor complex exhibit antidepressant actions. Eur J Pharmacol 1990; 185: 1-10.

16. Paul IA, Skolnick P. Glutamate and depression: clinical and preclinical studies. Ann NY Acad Sci 2003; 1003: 250-272.

17. Berman RM, Cappiello A, Anand A, Oren DA, Heninger GR, Charney DS et al. Antidepressant effects of ketamine in depressed patients. Biol Psychiatry 2000; 47: 351-354.

18. Zarate Jr CA, Singh JB, Carlson PJ, Brutsche NE, Ameli R, Luckenbaugh DA et al. A randomized trial of an $\mathrm{N}$-methyl-D-aspartate antagonist in treatment-resistant major depression. Arch Gen Psychiatry 2006; 63: 856-864.

19. Price RB, Nock MK, Charney DS, Mathew SJ. Effects of intravenous ketamine on explicit and implicit measures of suicidality in treatment-resistant depression. Biol Psychiatry 2009; 66: 522-526.

20. Preskorn SH, Baker B, Kolluri S, Menniti FS, Krams M, Landen JW. An innovative design to establish proof of concept of the antidepressant effects of the GluN2B subunit selective $\mathrm{N}$-methyl-D-aspartate antagonist, CP-101,606, in patients with treatment-refractory major depressive disorder. J Clin Psychopharmacol 2008; 28: 631-637.

21. Liu J, Garza JC, Bronner J, Kim CS, Zhang W, Lu XY. Acute administration of leptin produces anxiolytic-like effects: a comparison with fluoxetine. Psychopharmacology (Berl) 2010; 207: 535-545.

22. Lu XY, Kim CS, Frazer A, Zhang W. Leptin: a potential novel antidepressant. Proc Natl Acad Sci USA 2006; 103: 1593-1598.

23. Yamada N, Katsuura G, Ochi Y, Ebihara K, Kusakabe T, Hosoda K et al. Impaired CNS leptin action is implicated in depression associated with obesity. Endocrinology 2011: 152: 2634-2643.

24. Finger BC, Dinan TG, Cryan JF. High-fat diet selectively protects against the effects of chronic social stress in the mouse. Neuroscience 2011; 192: 351-360.

25. Jow GM, Yang TT, Chen CL. Leptin and cholesterol levels are low in major depressive disorder, but high in schizophrenia. J Affect Disord 2006; 90: 21-27. 
26. Kraus T, Haack M, Schuld A, Hinze-Selch D, Pollmacher T. Low leptin levels but normal body mass indices in patients with depression or schizophrenia. Neuroendocrinology 2001; 73: 243-247.

27. Yang K, Xie G, Zhang Z, Wang C, Li W, Zhou W et al. Levels of serum interleukin (IL)-6, IL-1beta, tumour necrosis factor-alpha and leptin and their correlation in depression. Aust N Z J Psychiatry 2007; 41: 266-273.

28. Lawson EA, Miller KK, Blum Jl, Meenaghan E, Misra M, Eddy KT et al. Leptin levels are associated with decreased depressive symptoms in women across the weight spectrum, independent of body fat. Clin Endocrinol (Oxf) 2011; doi: 10.1111/j.1365-2265.2011. 04182.x.

29. Scott MM, Lachey JL, Sternson SM, Lee CE, Elias CF, Friedman JM et al. Leptin targets in the mouse brain. J Comp Neurol 2009; 514: 518-532.

30. Caron E, Sachot C, Prevot V, Bouret SG. Distribution of leptin-sensitive cells in the postnatal and adult mouse brain. J Comp Neurol 2010; 518: 459-476.

31. Patterson CM, Leshan RL, Jones JC, Myers Jr MG. Molecular mapping of mouse brain regions innervated by leptin receptor-expressing cells. Brain Res 2011; 1378: 18-28.

32. Campbell S, Macqueen $\mathrm{G}$. The role of the hippocampus in the pathophysiology of major depression. J Psychiatry Neurosci 2004; 29: 417-426.

33. Koenigs M, Grafman J. The functional neuroanatomy of depression: distinct roles for ventromedial and dorsolateral prefrontal cortex. Behav Brain Res 2009; 201 239-243.

34. Soares JC, Mann JJ. The anatomy of mood disorders-review of structural neuroimaging studies. Biol Psychiatry 1997; 41: 86-106.

35. Chan CH, Godinho LN, Thomaidou D, Tan SS, Gulisano M, Parnavelas JG. Emx1 is a marker for pyramidal neurons of the cerebral cortex. Cereb Cortex 2001; 11: 1191-1198.

36. Gorski JA, Talley T, Qu M, Puelles L, Rubenstein JL, Jones KR. Cortical excitatory neurons and glia, but not GABAergic neurons, are produced in the Emx1-expressing lineage. J Neurosci 2002; 22: 6309-6314.

37. Iwasato T, Nomura R, Ando R, Ikeda T, Tanaka M, Itohara S. Dorsal telencephalonspecific expression of Cre recombinase in PAC transgenic mice. Genesis 2004; 38: 130-138.

38. McMinn JE, Liu SM, Dragatsis I, Dietrich P, Ludwig T, Eiden S et al. An allelic series for the leptin receptor gene generated by CRE and FLP recombinase. Mamm Genome 2004 15: 677-685.

39. Guo H, Hong S, Jin XL, Chen RS, Avasthi PP, Tu YT et al. Specificity and efficiency of Cre-mediated recombination in Emx1-Cre knock-in mice. Biochem Biophys Res Commun 2000; 273: 661-665.

40. Jin XL, Guo H, Mao C, Atkins N, Wang H, Avasthi PP et al. Emx1-specific expression of foreign genes using 'knock-in' approach. Biochem Biophys Res Commun 2000; 270 978-982.

41. Tsankova NM, Berton O, Renthal W, Kumar A, Neve RL, Nestler EJ. Sustained hippocampal chromatin regulation in a mouse model of depression and antidepressant action. Nat Neurosci 2006; 9: 519-525.

42. Koolhaas JM, De Boer SF, De Rutter AJ, Meerlo P, Sgoifo A. Social stress in rats and mice. Acta Physiol Scand Suppl 1997; 640: 69-72.

43. Martinez M, Calvo-Torrent A, Pico-Alfonso M. Social defeat and subordination as models of social stress in laboratory rodents: a review. Aggress Behav 1998; 24: 241-256.

44. Yu T, Guo M, Garza J, Rendon S, Sun XL, Zhang W et al. Cognitive and neural correlates of depression-like behaviour in socially defeated mice: an animal model of depression with cognitive dysfunction. Int J Neuropsychopharmacol 2011; 14: 303-317.

45. Liu J, Perez SM, Zhang W, Lodge DJ, Lu XY. Selective deletion of the leptin receptor in dopamine neurons produces anxiogenic-like behavior and increases dopaminergic activity in amygdala. Mol Psychiatry 2011; 16: 1024-1038.

46. Garza JC, Guo M, Zhang W, Lu XY. Leptin increases adult hippocampal neurogenesis in vivo and in vitro. J Biol Chem 2008; 283: 18238-18247.

47. Liu J, Garza JC, Truong HV, Henschel J, Zhang W, Lu XY. The melanocortinergic pathway is rapidly recruited by emotional stress and contributes to stress-induced anorexia and anxiety-like behavior. Endocrinology 2007; 148: 5531-5540.

48. Garza JC, Kim CS, Liu J, Zhang W, Lu XY. Adeno-associated virus-mediated knockdown of melanocortin-4 receptor in the paraventricular nucleus of the hypothalamus promotes high-fat diet-induced hyperphagia and obesity. J Endocrinol 2008; 197: 471-482.

49. Porsolt RD, Bertin A, Jalfre M. Behavioral despair in mice: a primary screening test for antidepressants. Arch Int Pharmacodyn Ther 1977; 229: 327-336.

50. Steru L, Chermat R, Thierry B, Simon P. The tail suspension test: a new method for screening antidepressants in mice. Psychopharmacology (Berl) 1985; 85: 367-370.

51. Cryan JF, Mombereau C, Vassout A. The tail suspension test as a model for assessing antidepressant activity: review of pharmacological and genetic studies in mice. Neurosci Biobehav Rev 2005; 29: 571-625

52. Petit-Demouliere $B$, Chenu $F$, Bourin $M$. Forced swimming test in mice: a review of antidepressant activity. Psychopharmacology (Berl) 2005; 177: 245-255.

53. Willner P, Muscat R, Papp M. Chronic mild stress-induced anhedonia: a realistic animal model of depression. Neurosci Biobehav Rev 1992; 16: 525-534.

54. Shanks N, Anisman H. Strain-specific effects of antidepressants on escape deficits induced by inescapable shock. Psychopharmacology (Berl) 1989; 99: 122-128.

55. Plotsky PM, Owens MJ, Nemeroff CB. Psychoneuroendocrinology of depression Hypothalamic-pituitary-adrenal axis. Psychiatr Clin North Am 1998; 21: 293-307.
56. Holsboer F. The corticosteroid receptor hypothesis of depression. Neuropsychopharmacology 2000; 23: 477-501.

57. Herman JP, Schafer MK, Young EA, Thompson R, Douglass J, Akil H et al. Evidence for hippocampal regulation of neuroendocrine neurons of the hypothalamo-pituitaryadrenocortical axis. J Neurosci 1989; 9: 3072-3082.

58. Jacobson L, Sapolsky R. The role of the hippocampus in feedback regulation of the hypothalamic-pituitary-adrenocortical axis. Endocr Rev 1991; 12: 118-134.

59. McEwen BS, Gianaros PJ. Stress- and allostasis-induced brain plasticity. Annu Rev Med 2011; 62: 431-445

60. Pittenger C, Duman RS. Stress, depression, and neuroplasticity: a convergence of mechanisms. Neuropsychopharmacology 2008; 33: 88-109.

61. Holderbach R, Clark K, Moreau JL, Bischofberger J, Normann C. Enhanced long-term synaptic depression in an animal model of depression. Biol Psychiatry 2007; 62: 92-100.

62. Wang M, Yang Y, Dong Z, Cao J, Xu L. GluN2B-containing N-methyl-D-aspartate subtype glutamate receptors regulate the acute stress effect on hippocampal long-term potentiation/long-term depression in vivo. NeuroReport 2006; 17: 1343-1346.

63. Niehusmann P, Seifert G, Clark K, Atas HC, Herpfer I, Fiebich B et al. Coincidence detection and stress modulation of spike time-dependent long-term depression in the hippocampus. J Neurosci 2010; 30: 6225-6235.

64. Dudek SM, Bear MF. Bidirectional long-term modification of synaptic effectiveness in the adult and immature hippocampus. J Neurosci 1993; 13: 2910-2918.

65. Mulkey RM, Malenka RC. Mechanisms underlying induction of homosynaptic long-term depression in area CA1 of the hippocampus. Neuron 1992; 9: 967-975.

66. Wagner JJ, Alger BE. GABAergic and developmental influences on homosynaptic LTD and depotentiation in rat hippocampus. J Neurosci 1995; 15: 1577-1586.

67. Kamal A, Ramakers GM, Urban IJ, De Graan PN, Gispen WH. Chemical LTD in the CA1 field of the hippocampus from young and mature rats. Eur $J$ Neurosci 1999; 11 3512-3516.

68. Lee HK, Kameyama K, Huganir RL, Bear MF. NMDA induces long-term synaptic depression and dephosphorylation of the GluR1 subunit of AMPA receptors in hippocampus. Neuron 1998; 21: 1151-1162.

69. Thiels E, Xie X, Yeckel MF, Barrionuevo G, Berger TW. NMDA receptor-dependent LTD in different subfields of hippocampus in vivo and in vitro. Hippocampus 1996; 6: 43-51.

70. Tovar KR, Westbrook GL. The incorporation of NMDA receptors with a distinct subunit composition at nascent hippocampal synapses in vitro. J Neurosci 1999; 19 4180-4188

71. Kim JJ, Foy MR, Thompson RF. Behavioral stress modifies hippocampal plasticity through N-methyl-D-aspartate receptor activation. Proc Natl Acad Sci USA 1996; 93 4750-4753.

72. Xu L, Anwyl R, Rowan MJ. Behavioural stress facilitates the induction of long-term depression in the hippocampus. Nature 1997; 387: 497-500.

73. Wong TP, Howland JG, Robillard JM, Ge Y, Yu W, Titterness AK et al. Hippocampal longterm depression mediates acute stress-induced spatial memory retrieval impairment. Proc Natl Acad Sci USA 2007; 104: 11471-11476.

74. Von Frijtag JC, Kamal A, Reijmers LG, Schrama LH, van den Bos R, Spruijt BM. Chronic imipramine treatment partially reverses the long-term changes of hippocampal synaptic plasticity in socially stressed rats. Neurosci Lett 2001; 309: 153-156.

75. Oomura Y, Hori N, Shiraishi T, Fukunaga K, Takeda H, Tsuji M et al. Leptin facilitates learning and memory performance and enhances hippocampal CA1 long-term potentiation and CaMK II phosphorylation in rats. Peptides 2006; 27: 2738-2749.

76. Wayner MJ, Armstrong DL, Phelix CF, Oomura Y. Orexin-A (Hypocretin-1) and leptin enhance LTP in the dentate gyrus of rats in vivo. Peptides 2004; 25: 991-996.

77. Walker $\mathrm{CD}$, Long $\mathrm{H}$, Williams $\mathrm{S}$, Richard $\mathrm{D}$. Long-lasting effects of elevated neonatal leptin on rat hippocampal function, synaptic proteins and NMDA receptor subunits. J Neurosci Res 2007; 85: 816-828.

78. Li XL, Aou S, Oomura Y, Hori N, Fukunaga K, Hori T. Impairment of long-term potentiation and spatial memory in leptin receptor-deficient rodents. Neuroscience 2002; 113 607-615

79. Gerges NZ, Aleisa AM, Alkadhi KA. Impaired long-term potentiation in obese zucker rats: possible involvement of presynaptic mechanism. Neuroscience 2003; 120: 535-539.

80. Stranahan AM, Arumugam TV, Cutler RG, Lee K, Egan JM, Mattson MP. Diabetes impairs hippocampal function through glucocorticoid-mediated effects on new and mature neurons. Nat Neurosci 2008; 11: 309-317.

81. Chen $\mathrm{H}$, Charlat O, Tartaglia LA, Woolf EA, Weng X, Ellis SJ et al. Evidence that the diabetes gene encodes the leptin receptor: identification of a mutation in the leptin receptor gene in db/db mice. Cell 1996; 84: 491-495.

82. Lee GH, Proenca R, Montez JM, Carroll KM, Darvishzadeh JG, Lee Jl et al. Abnormal splicing of the leptin receptor in diabetic mice. Nature 1996; 379: 632-635.

83. Tartaglia LA, Dembski M, Weng X, Deng N, Culpepper J, Devos R et al. Identification and expression cloning of a leptin receptor, OB-R. Cell 1995; 83: 1263-1271.

84. Alfarez DN, Wiegert O, Joels M, Krugers HJ. Corticosterone and stress reduce synaptic potentiation in mouse hippocampal slices with mild stimulation. Neuroscience 2002; 115 1119-1126.

85. Biessels GJ, Kamal A, Ramakers GM, Urban IJ, Spruijt BM, Erkelens DW et al. Place learning and hippocampal synaptic plasticity in streptozotocin-induced diabetic rats. Diabetes 1996; 45: 1259-1266. 
86. Diamond DM, Bennett MC, Fleshner M, Rose GM. Inverted-U relationship between the level of peripheral corticosterone and the magnitude of hippocampal primed burst potentiation. Hippocampus 1992; 2: 421-430.

87. Huang CC, Lee CC, Hsu KS. An investigation into signal transduction mechanisms involved in insulin-induced long-term depression in the CA1 region of the hippocampus J Neurochem 2004; 89: 217-231.

88. Man HY, Lin JW, Ju WH, Ahmadian G, Liu L, Becker LE et al. Regulation of AMPA receptor-mediated synaptic transmission by clathrin-dependent receptor internalization. Neuron 2000; 25: 649-662.

89. Pavlides C, Kimura A, Magarinos AM, McEwen BS. Hippocampal homosynaptic long-term depression/depotentiation induced by adrenal steroids. Neuroscience 1995; 68: 379-385

90. van der Heide LP, Kamal A, Artola A, Gispen WH, Ramakers GM. Insulin modulates hippocampal activity-dependent synaptic plasticity in a $\mathrm{N}$-methyl-d-aspartate receptor and phosphatidyl-inositol-3-kinase-dependent manner. J Neurochem 2005; 94: 1158-1166.

91. Brigman JL, Wright T, Talani G, Prasad-Mulcare S, Jinde S, Seabold GK et al. Loss of GluN2B-containing NMDA receptors in CA1 hippocampus and cortex impairs long-term depression, reduces dendritic spine density, and disrupts learning. J Neurosci 2010; 30 4590-4600.

92. Collingridge GL, Peineau S, Howland JG, Wang YT. Long-term depression in the CNS Nat Rev Neurosci 2010; 11: 459-473.

93. Kemp A, Manahan-Vaughan D. Hippocampal long-term depression: master or minion in declarative memory processes? Trends Neurosci 2007; 30: 111-118.

94. Massey PV, Bashir ZI. Long-term depression: multiple forms and implications for brain function. Trends Neurosci 2007; 30: 176-184.

95. Nicholls RE, Alarcon JM, Malleret G, Carroll RC, Grody M, Vronskaya S et al. Transgenic mice lacking NMDAR-dependent LTD exhibit deficits in behavioral flexibility. Neuron 2008; 58: 104-117

96. Simon GE, Von Korff M, Saunders K, Miglioretti DL, Crane PK, van Belle G et al. Association between obesity and psychiatric disorders in the US adult population. Arch Gen Psychiatry 2006; 63: 824-830.

97. Kivimaki M, Lawlor DA, Singh-Manoux A, Batty GD, Ferrie JE, Shipley MJ et al. Common mental disorder and obesity: insight from four repeat measures over 19 years: prospective Whitehall II cohort study. BMJ 2009; 339: b3765.

98. Markowitz S, Friedman MA, Arent SM. Understanding the relation between obesity and depression: causal mechanisms and implications for treatment. Clin Psychol Sci Pract 2008; 15: 1-20.

99. Luppino FS, de Wit LM, Bouvy PF, Stijnen T, Cuijpers P, Penninx BW et al. Overweight, obesity, and depression: a systematic review and meta-analysis of longitudinal studies. Arch Gen Psychiatry 2010; 67: 220-229.

100. McElroy SL, Kotwal R, Malhotra S, Nelson EB, Keck PE, Nemeroff CB. Are mood disorders and obesity related? A review for the mental health professional. J Clin Psychiatry 2004; 65: 634-651, quiz 730.

101. Vucetic Z, Kimmel J, Reyes TM. Chronic high-fat diet drives postnatal epigenetic regulation of mu-opioid receptor in the brain. Neuropsychopharmacology 2011; 36: 1199-1206.
102. Clement K, Vaisse C, Lahlou N, Cabrol S, Pelloux V, Cassuto D et al. A mutation in the human leptin receptor gene causes obesity and pituitary dysfunction. Nature 1998; 392 : 398-401.

103. Cohen $\mathrm{P}$, Zhao C, Cai X, Montez JM, Rohani SC, Feinstein P et al. Selective deletion of leptin receptor in neurons leads to obesity. J Clin Invest 2001; 108: 1113-1121.

104. de Luca C, Kowalski TJ, Zhang Y, Elmquist JK, Lee C, Kilimann MW et al. Complete rescue of obesity, diabetes, and infertility in $\mathrm{db} / \mathrm{db}$ mice by neuron-specific LEPR-B transgenes. J Clin Invest 2005; 115: 3484-3493.

105. Faroogi IS, Wangensteen T, Collins S, Kimber W, Matarese G, Keogh JM et al. Clinical and molecular genetic spectrum of congenital deficiency of the leptin receptor. $N$ Engl $J$ Med 2007; 356: 237-247.

106. Gibson WT, Faroogi IS, Moreau M, DePaoli AM, Lawrence E, O'Rahilly S et al. Congenital leptin deficiency due to homozygosity for the Delta133G mutation: report of another case and evaluation of response to four years of leptin therapy. J Clin Endocrinol Metab 2004; 89: 4821-4826.

107. Montague CT, Farooqi IS, Whitehead JP, Soos MA, Rau $H$, Wareham NJ et al. Congenital leptin deficiency is associated with severe early-onset obesity in humans. Nature 1997; 387: 903-908.

108. Ozata M, Ozdemir IC, Licinio J. Human leptin deficiency caused by a missense mutation: multiple endocrine defects, decreased sympathetic tone, and immune system dysfunction indicate new targets for leptin action, greater central than peripheral resistance to the effects of leptin, and spontaneous correction of leptin-mediated defects. J Clin Endocrinol Metab 1999; 84: 3686-3695.

109. Strobel A, Issad T, Camoin L, Ozata M, Strosberg AD. A leptin missense mutation associated with hypogonadism and morbid obesity. Nat Genet 1998; 18: 213-215.

110. Zhang Y, Proenca R, Maffei M, Barone M, Leopold L, Friedman JM. Positional cloning of the mouse obese gene and its human homologue. Nature 1994; 372: 425-432.

111. Chen $Y$, Jiang $Y$, Mao $Y$. Association between obesity and depression in Canadians. $J$ Womens Health (Larchmt) 2009; 18: 1687-1692.

112. de Wit LM, van Straten A, van Herten M, Penninx BW, Cuijpers P. Depression and body mass index, a u-shaped association. BMC Public Health 2009; 9: 14

113. McCrea RL, Berger YG, King MB. Body mass index and common mental disorders: exploring the shape of the association and its moderation by age, gender and education. Int J Obes (Lond) 2011; doi: 10.1038/ijo.2011.65.

Translational Psychiatry is an open-access journal published by Nature Publishing Group. This work is licensed under the Creative Commons Attribution-Noncommercial-No Derivative Works 3.0 Unported License. To view a copy of this license, visit http://creativecommons.org/licenses/by-nc-nd/3.0/

Supplementary Information accompanies the paper on the Translational Psychiatry website (http://www.nature.com/tp) 